\title{
The Loricrin-Like Protein (LLP) of Phytophthora infestans Is Required for Oospore Formation and Plant Infection
}

\author{
Ting Guo, Xiao-Wen Wang, Kun Shan, Wenxian Sun and Li-Yun Guo* \\ Department of Plant Pathology and the Key Laboratory for Plant Pathology MOA, China Agricultural University, Beijing, China
}

\section{OPEN ACCESS}

Edited by:

Francine Govers,

Wageningen University and Research

Centre, Netherlands

Reviewed by:

Julio Vega-Arreguin,

National Autonomous University of

Mexico, Mexico

Pere Mestre,

Grapevine Health and Wine Quality

(INRA), France

*Correspondence:

Li-Yun Guo

ppguo@cau.edu.cn;

ppguoly@126.com

Specialty section:

This article was submitted to

Plant Microbe Interactions,

a section of the journal

Frontiers in Plant Science

Received: 24 October 2016

Accepted: 24 January 2017

Published: 09 February 2017

Citation:

Guo T, Wang X-W, Shan K, Sun W and Guo L-Y (2017) The Loricrin-Like

Protein (LLP) of Phytophthora

infestans Is Required for Oospore

Formation and Plant Infection.

Front. Plant Sci. 8:142.

doi: 10.3389/fp/s.2017.00142
Loricrin-like protein (LLP) is characterized by a high content of glycine residues and is a major component of plant cell wall. Here, we identified a Phytophthora infestans ortholog of plant $L L P$, named PiLLP. In $P$. infestans, PiLLP is strongly expressed in asexual and sexual developmental stages, including in sporangia, zoospores and germinating cysts, and during oospore formation, as well as in the early stages of infection and during hydrogen peroxide stress. Compared with the wild type, the PiLLP-silenced transformants were defective in oospore formation, had slower colony expansion rates, produced less sporangia with lower germination and zoospore-release rates, and were more sensitive to hydrogen peroxide. Moreover, Nile red staining, and PiLLP-red fluorescent protein fusions indicated that PiLLP is involved in oogonia formation. The silenced transformants also had severely diminished virulence levels that could be partially restored with diphenyleneiodium treatments. The analysis of catalase activity showed a decrease of catalase activity in silenced transformants. Thus, PiLLP is important for sexual and asexual reproduction, and is required for oxidative stress tolerance and plant infection.

Keywords: sexual reproduction, oxidative stress, reactive oxygen species, pathogenicity, Phytophthora infestans, DPI

\section{INTRODUCTION}

The oomycetes form a group of fungus-like eukaryotes containing diverse microorganisms that live in saltwater, freshwater, and terrestrial environments (Sparrow, 1960; Karling, 1981). A phylogenetic analysis showed that oomycetes belong to the Stramenopila kingdom, along with photosynthetic chromistan algae (Sogin and Silberman, 1998; Baldauf et al., 2000; Yoon et al., 2002; Adl et al., 2005). Many members of the oomycetes are well-known pathogens of plants and animals, causing severe economic losses. Phytophthora infestans (Mont.) de Bary is the causal agent of potato late blight, which is a devastating disease worldwide and the causal agent of the Irish potato famine of the Nineteenth century (Bourke, 1993).

$P$. infestans reproduces asexually by forming sporangia on sporangiophores. Sporangia are readily dehiscent, particularly in response to changes in relative humidity (Aylor et al., 2001). Sporangia in free water germinate directly either via germ tubes at higher temperatures (20$25^{\circ} \mathrm{C}$ ), or by releasing zoospores at lower temperatures $\left(10-15^{\circ} \mathrm{C}\right)$ (Ribeiro, 1983). The asexual cycle enables dramatically rapid population growth in susceptible host tissue. Both sporangia and zoospores are important for infection and enable the movement of $P$. infestans between host plants. 
As a heterothallic oomycete, $P$. infestans requires the presence of both mating types, as in "MX5-1" (A1 mating type) and "80787-94L" (A2 mating type), to complete sexual reproduction by producing oospores. The thick-walled oospores can overcome harsh environmental conditions, such as cold, chemical fumigation, and microbial degradation, surviving in soil or plant debris for many years. They then serve as primary inocula in the following years (Mayton et al., 2000; Turkensteen et al., 2000; Prakob and Judelson, 2007). Moreover, the gene recombination resulting from sexual reproduction may generate new virulent strains making disease management more difficult (Gavino et al., 2000). Although some genes involved in the sexual reproduction of Phytophthora have been screened (Fabritius et al., 2002; Prakob and Judelson, 2007; Zhao et al., 2011), the biological functions of these genes have not been explored.

Generally, $P$. infestans is regarded as a hemi-biotrophic pathogen that displays host specificity. Many pathogenicity factors have been identified to be essential for successful infection and colonization of the host, including the cytoplasmic RXLR effector Avr3a (Sanju et al., 2015), the bZIP transcription factors (Gamboa-Meléndez et al., 2013), the carbohydrate-active enzymes (Brouwer et al., 2014) and endopolygalacturonase (Torto et al., 2002).

During evolution, plants developed a sophisticated defense system to counter microbial invasions. Upon infection, plants defend themselves through biochemical reactions, such as the accumulation of reactive oxygen species (ROS) at the plant surface (Apostol et al., 1989). The production of ROS is catalyzed by nicotinamide adenine dinucleotide phosphate (NADPH) oxidases that are localized in the plasma membrane (Doke et al., 1996). To successfully infect the host plant, pathogens have to scavenge the plant-derived ROS (Apel and Hirt, 2004). Recently, effectors, mitogen-activated protein kinases (MAPKs), heatshock proteins and bZIP transcription factors in Phytophthora spp. have been proven to be involved in ROS scavenging (Dong et al., 2011; Gamboa-Meléndez et al., 2013; Gao et al., 2015; Sheng et al., 2015). In total, five catalase genes are encoded in the genome of $P$. infestans. A transcriptome analysis of $P$. infestans has revealed that catalase genes (PITG_15248 and PITG_07143) were up-regulated during early infection stages (Haas et al., 2009). Thus, ROS scavenging maybe important for P. infestans pathogenesis.

Loricrin is a type of glycine-, serine-, and cysteine-rich protein found in animals and is a major component of the cornified cell envelope (CE) in terminally differentiating structures (Hohl et al., 1993). Its major function is to strengthen the $\mathrm{CE}$ and the defensive barrier (Nithya et al., 2015). The glycine-rich proteins (GRPs) are loricrin-like proteins (LLPs) found in plants (Goddemeier et al., 1998). GRP is a major component of plant cell walls (Cassab, 1998) and is speculated to play important roles in the development of vascular tissues, nodules and flowers (Ryser and Keller, 1992; de Oliveira et al., 1993; Küster et al., 1995; Ryser et al., 1997). Currently, in plants, five classes of GRPs have been defined based on the arrangement of the glycine repeats and the type of conserved motifs (Mangeon et al., 2010, 2016). The Class I GRPs have a high glycine-content region of $(\mathrm{GGX})_{\mathrm{n}}$ repeats, such as the French bean PvGRP1.8, which performs a structural role in the cell wall as a part of the protoxylem repair system (Ringli et al., 2001). The Class II GRPs contain a characteristic cysteine-rich C-terminus, as seen in NtCIG1 in tobacco, which enhances the callose deposition in cells (Ueki and Citovsky, 2002). The Class III GRPs have an oleosin domain, like that in AtOGB3, which is required for pollen hydration and competition (Mayfield and Preuss, 2000). Class IV GRPs are also known as RNA-binding GRPs, like AtCSG2, which is implicated in cold, salt, and osmotic stresses (Park et al., 2009). The Class V GRPs, containing mixed patterns of repeats, have been identified in eucalyptus (Bocca et al., 2005), but their functions are unknown.

By mining the microarray data obtained by Prakob and Judelson (2007), we found a novel gene encoding a LLP, which has not been studied before. As it was highly expressed during the sexual development of $P$. infestans, we suspected it played an important role in oospore formation. Here, we investigated the biological roles of this LLP gene in P. infestans using gene silencing and over-expression techniques. Our study provides insights into the LLP's function during oospore formation and the pathogenesis of oomycetes.

\section{MATERIALS AND METHODS}

\section{Phylogenetic Analysis}

Gene sequences of oomycete species used in this study were retrieved from the database of the DOE Joint Genome Institute (http://www.jgi.doe.gov/) and the EnsemblGenomes (http:// www.ensemblgenomes.org/). Based on additional searches genes of diatoms (Thalassiosira pseudonana), protists (Tetrahymena thermophile, Paramecium tetraurelia), and plants (Arabidopsis thaliana, Sorhum bicolor, Zea mays, Oryza sativa) were retrieved from the NCBI and KEGG databases (Table S1). Multiple alignments of the amino acid sequences were performed using ClustalW2 (http://www.ebi.ac.uk/Tools/msa/clustalw2/; Larkin et al., 2007). Phylogenetic trees were constructed with the maximum likelihood evolution algorithm in MEGA 5.22 (Tamura et al., 2011). A Poisson correction was used for multiple substitution models and pairwise deletion was used for gap split data treatment. The statistical strengths were assessed by bootstraps with 1000 replicates.

\section{$P$. infestans Strains and Culture Conditions}

The "MX5-1" (A1 mating type; Han et al., 2012) and "80787-94L" (A2 mating type; Guo et al., 2010) isolates of $P$. infestans were used in this study. The WT strain and silenced transformants were maintained on tomato rye agar (TRA) medium (Guo et al., 2010) at $18^{\circ} \mathrm{C}$ in the darkness. Oospores were obtained by pairing "MX5-1" (A1 mating type) and "80787-94L" (A2 mating type) on TRA plates kept in the darkness for 7,11 , and 17 days. To test the mycelial growth rate, culture blocks ( $5 \mathrm{~mm}$ in diameter) cut from the edge of an actively growing culture were inoculated on the TRA plate at $18^{\circ} \mathrm{C}$ in the darkness, and the colony diameters were measured after a 7-day incubation. Sporangia of each strain were collected by washing 12-day-old cultures with pea broth. Zoospores were generated by incubating the sporangia suspension first at $4^{\circ} \mathrm{C}$ for $2 \mathrm{~h}$ and then at room temperature for $1 \mathrm{~h}$. To test the oxidative sensitivity of each strain, culture 
blocks (5 $\mathrm{mm}$ in diameter) were placed on fresh TRA plates supplemented with $0.5,1.0,1.5$, and $2.0 \mathrm{mM} \mathrm{H}_{2} \mathrm{O}_{2}$. The colony diameters were then measured after incubating the culture at $18^{\circ} \mathrm{C}$ in the darkness for 7 days. All of the experiments were performed twice, and each treatment was repeated in triplicate.

\section{RNA Extraction and Gene Expression Analysis}

To determine the transcript profiles of the PiLLP gene in various stages of sexual development, the "MX5-1" (A1 mating type) and "80787-94L" (A2 mating type) isolates were incubated 2-cm apart from each other on polycarbonate membranes with $0.4 \mu \mathrm{m}$ pores (Merck Millipore Ltd., Tullagreen, Ireland) overlaid on the surface of TRA plates and incubated at $18^{\circ} \mathrm{C}$ in the darkness. Each of these isolates, paired similarly with itself and cultured under the same conditions, was used as control. After 4, 6, 8, 10,12 , and 14 days, mycelia, and mycelia with oospores, were harvested from the junction area between the inoculation sites in each plate and were then ground in liquid nitrogen. The total RNA of each sample was extracted using a NucleoSpin RNA Plant kit (MACHEREY-NAGEL, Düren, Germany), and was reversely transcribed with an oligo $(\mathrm{dT})_{18}$ primer using the Reverse Transcriptase M-MLV (TaKaRa Bio Inc. Shiga, Japan) following the manufacturer's instructions. SYBR Green real-time qPCRs were performed in an ABI 7500 detection system (Applied Biosystems, Foster City, CA, USA). The elongation factor 1 (ef1) gene of $P$. infestans was used as an internal control. Means and standard deviations were calculated using data from three replicates. The whole experiment was repeated with a different set of biological samples.

\section{Plasmid Construction and the Generation of $P$. infestans Transformants}

We used the plasmid vector pTORmRFP4 to construct transformation plasmids. The $5^{\prime} \mathrm{UTR}, 3^{\prime} \mathrm{UTR}$, and ORF regions of PiLLP were amplified from the CDNA of $P$. infestans "MX51" with specific primers (Table S2). The amplified fragments of $5^{\prime}$ UTR and 3'UTR were joined by fusion PCR, and then inserted in an anti-sense orientation into pTORmRFP4 for silencing. The ORF of PiLLP was inserted in the sense orientation for overexpression. The plasmid constructs were all verified by DNA sequencing. Transformation of the P. infestans strain "MX5-1" was performed as described previously (Mcleod et al., 2008). To validate the transformants, PiLLP transcript levels during the growth of mycelia were measured by qRT-PCR.

\section{Tetrazolium Bromide Staining}

Oospores from STs (PiLLP-silenced transformants), CK (the transformant carrying the empty vector pTORmRFP4) and WT (MX5-1) strains were obtained as described above. MTT staining was performed by mixing the oospore suspension with equivalent volumes of $0.1 \%$ MTT (Sigma-Aldrich, St. Louis, MO, USA) in $0.1 \mathrm{M} \mathrm{PBS}$ ( $\mathrm{pH} \mathrm{5.8),} \mathrm{and} \mathrm{incubated} \mathrm{at} 37^{\circ} \mathrm{C}$ for $24 \mathrm{~h}$ before observing under an Olympus BX41 microscope (Olympus, Tokyo, Japan). The oospores in red or purple were considered to be dormant viable, whereas the black and unstained oospores were non-viable (Ribeiro, 1978).

\section{Nile Red Staining}

The distribution of lipid bodies in oospores was determined using Nile red staining. The Nile red stock solution (1 mM) was prepared by dissolving $100 \mathrm{mg}$ of Nile red powder (SigmaAldrich, St. Louis, MO, USA) in $314 \mathrm{ml}$ of methanol. Before staining, $10 \mu \mathrm{l}$ of stock solutions were diluted $20 \times$ with dimethylsulphoxide (DMSO). An aliquot of $20 \mu$ l oospore suspension was mixed with an equal volume of diluted Nile red solution on a microscope slide, and incubated at room temperature for $5 \mathrm{~min}$, followed by two washes with PBS ( $\mathrm{pH}$ 5.8). The samples were then viewed under an Olympus FluoView ${ }^{\mathrm{TM}}$ FV1000 confocal laser scanning microscope (Olympus, Tokyo, Japan) with an excitation wavelength of $530 \mathrm{~nm}$ and an emission wavelength of $568 \mathrm{~nm}$.

\section{Trypan Blue Staining}

Trypan blue staining was performed as described by Koch and Slusarenko (1990). Infected leaves were stained with lactophenoltrypan blue ( $10 \mathrm{ml}$ of lactic acid, $10 \mathrm{ml}$ of glycerol, $10 \mathrm{~g}$ of phenol, and $10 \mathrm{mg}$ of trypan blue dissolved in $10 \mathrm{ml}$ of distilled water). The leaves were boiled for $\sim 2 \mathrm{~min}$ in the staining solution and then destained in $2.5 \mathrm{~g} / \mathrm{ml}$ chloral hydrate for 30-40 min.

\section{3, 3-Diaminobenzidine (DAB) Staining}

ROS were stained with the oxidant-sensitive probe DAB (SigmaAldrich, St. Louis, MO, USA) as described by Liu and Friesen (2012). Detached Nicotiana benthamiana leaves were inoculated with the sporangia of WT, CK, and transformants. After $12 \mathrm{~h}$, the leaves were incubated in $1 \mathrm{mg} / \mathrm{ml} \mathrm{DAB}$ solution ( $\mathrm{pH} 3.8$ ) at room temperature for $8 \mathrm{~h}$, and were destained with ethanol, followed by viewing using an Olympus Bx41 microscope (Olympus, Tokyo, Japan).

\section{Pathogenicity Test}

For plant inoculations, WT (MX5-1), CK, STs, and OTs (PiLLPoverexpressed transformants) strains were incubated on TRA medium- plates in the darkness for 14 days. Sporangia of each strain were collected by washing 12-day-old cultures with pea broth. A $20-\mu 1$ droplet of a sporangial suspension of $1 \times 10^{4}$ sporangia/ml for WT, CK, and OTs and $2 \times 10^{4}$ sporangia/ml for ST strains was inoculated on a detached potato (cv. Impala) leaf. Three detached leaves placed on a moist filter paper in a Petri dish were used as a replicate, and three plates were used for each treatment. Inoculated leaves were then incubated at $21^{\circ} \mathrm{C}$ with a 12-h/12-h light/ dark cycle for 5 days. The size of each lesion was measured and analyzed with Student's $t$-test. The experiments were performed twice.

\section{DPI Infiltration}

DPI, a flavoenzyme inhibitor, inhibits the activities of the plant NADPH oxidases that are necessary for ROS generation (Cross and Jones, 1986). To scavenge the host-derived ROS, leaves of potato (cv. Impala) were infiltrated with $0.5 \mu \mathrm{M}$ DPI (SigmaAldrich, St. Louis, MO, USA) in 0.05\% DMSO using a disposable, plastic needleless syringe. The leaves that were infiltrated with 0.05\% DMSO served as controls (Eloy et al., 2015). 


\section{Electron Microscopy}

We used scanning electron microscopy (SEM) to observe the surfaces of oogonial walls in WT, CK and ST strains. Oospores were harvested as described early from 11-day-old cultures grown on TRA medium, and samples were prepared as described by Ho (1979). Images were obtained using a HitachiS-3400N (Hitachi, Tokyo, Japan).

\section{In-Gel Assay for Activity of Catalase}

In order to investigate the catalase activity of WT, CK, and transformants, mycelia cultured in Pea Broth $(200 \mathrm{~g} / \mathrm{L})$ for 4 days were collected through filtration. Each sample was ground in liquid nitrogen and then mixed with ice-cold extraction buffer containing $50 \mathrm{mM}$ HEPES (pH7.4), $137 \mathrm{mM} \mathrm{NaCl}, 10 \%$ Glycerol and protease inhibitors, Pepstatin A $(1 \mu \mathrm{g} / \mathrm{mL})$, Leupeptin (1 $\mu \mathrm{g} / \mathrm{mL})$, PMSF (1 mM). Mixtures were centrifuged at 10,000 g for $10 \mathrm{~min}$ at $4^{\circ} \mathrm{C}$. Supernatant was collected and used as crude extract (Wang et al., 2016). The protein concentration was calculated based on the absorbance at $595 \mathrm{~nm}$ with Bio-Rad protein assay dye.

In-gel assay was performed as described previously (Lledias et al., 1998). Equal amounts of total protein $(20 \mu \mathrm{g})$ of different strains (WT, CK, STs, and OTs) were loaded into a $7.5 \%$ native polyacrylamide slab gel. The gel was immersed in $7 \mathrm{mM} \mathrm{H}_{2} \mathrm{O}_{2}$ for $10 \mathrm{~min}$ after electrophoresis, and then incubated in a $1 / 1$ mixture of freshly prepared $1 \%$ potassium hexacyanoferrate (III) and $1 \%$ iron (III) chloride hexahydrate. Blue color was observed in the gel except at zones where $\mathrm{H}_{2} \mathrm{O}_{2}$ was decomposed by catalases (Harris and Hopkinson, 1987).

\section{RESULTS}

\section{LLP Is a Conserved Gene in Oomycetes}

We identified a gene encoding LLP in P. infestans, and designated it as PiLLP (http://protists.ensembl.org/Phytophthora_infestans/

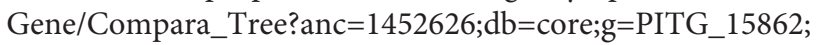
g1=BN9_002120;r=supercont1.39:614858-615784;t=PITG_ 15862T0, gene ID: PITG_15862). The PiLLP gene is 927 bp in length and encodes a protein of 308 amino acids (aa) with a glycine content of $12.7 \%$. Only one homolog of PiLLP was found in each oomycete genome, and a phylogenetic analysis showed that all of the oomycete LLPs were grouped into one clade, clustering with the Class V GRPs in plants (Figure 1A). A structural analysis showed that these LLPs contain mixed patterns of GGX/GXGX repeats, similar to the plant Class V GRPs (Figures 1B,C). However, the plant Class V GRPs are larger, around 600 aa, so almost double the size of the oomycete LPPs. These results suggest that the LLP genes are highly conserved in oomycetes and are phylogenetically related to the Class V GRPs of plants. No orthologs of oomycete or plant LLPs were found in fungi.

\section{The Expression Pattern of PiLLP in Different Stages}

To examine the expression pattern of PiLLP, we analyzed the transcript levels in $P$. infestans during sexual development (mating), asexual development (mycelia, sporangia, zoospores, cysts, and germinated cysts) and in planta growth (infection stages) using real-time qPCR. During mating, the PiLLP transcript level was up-regulated from 4 to 14 day, with the highest expression value at 10 day (Figure 2A; Table S4), and the PiLLP transcript level in sporangia was 80 -fold that in mycelia (Figure 2B; Table S4). During infection, the PiLLP expression was highest at $12-\mathrm{h}$ post-inoculation, then dropped and maintained a low level from 1-day post-inoculation (Figure 2B; Table S4). Thus, PiLLP may play important roles in reproduction and plant infection of $P$. infestans.

\section{Generation of PiLLP Transformants}

To investigate the function of PiLLP, PiLLP-silenced transformants (STs) and PiLLP-overexpressed transformants (OTs) were generated by polyethylene glycol-mediated protoplast transformation. The STs were generated with pTORmRFP4 vectors containing $5^{\prime}$ and $3^{\prime}$ untranslated regions (UTR) of PiLLP, whereas the OTs were generated with pTORmRFP4 vectors containing the PiLLP open reading frame (ORF) region. A transformant harboring the empty vector pTORmRFP4 was used as the control (CK). In total, three STs (S3, S16, and S84), three OTs (O15, O36, and O38), and a CK strain were used in this study. The expression levels of PiLLP in STs were from 10 to $45 \%$ of that in the WT strain, whereas the values in the OTs were significantly higher than those of WT and CK strains (Figure 3; Table S4).

\section{Sexual Phenotypes of PiLLP-Silenced Transformants}

All of the transformants, WT and CK were mated with the A2 mating-type isolate (80787-94L) on TRA medium to produce oospores. Less oospores were formed in paired-cultures of STs in comparison with the WT, CK, and OTs, and $\sim 45 \%$ (Table S3) of the oogonia in these ST strains did not form thick-walled oospores, whereas this was only $\sim 4 \%$ in WT, CK and OT cultures (Figures 4A,B).

To investigate the effects of PiLLP-silencing on oospore development, sexual apparatuses (oogonia-antheridia) formed in 7-, 11-, and 17-day-old cultures were investigated. Because the same A2 mating-type isolate (80787-94L) was used in all the pairings, the oogonia were referred as 7-, 11-, and 17-days-old for convenience. No obvious difference was found among the 7day-old oogonia of different strains (Figure 5A). However, about half of the 11-day-old oogonia of the STs showed a decline in the amount of cytoplasm in oogonia compared with those of the WT and CK strains at the same stage (Figure 5A). Moreover, the cytoplasm in $\sim 45 \%$ of the 17-day-old oogonia of the STs was completely void, without oospores, whereas the majority of the oogonia of WT and CK strains at the same stage contained mature thick-walled oospores (Figure 5A).

Subsequently, we determined the viability of oospores through tetrazolium bromide (MTT) staining. The 7-, 11-, and 17-dayold oospores of WT and CK strains, and the 7-day-old oogonia of the STs were stained purple (Figure 5B), indicating that they are viable. However, nearly half of the 11- and 17-dayold oogonia in the STs were black or unstained, suggesting the loss of viability (Figure 5B). Thus, some STs could form 


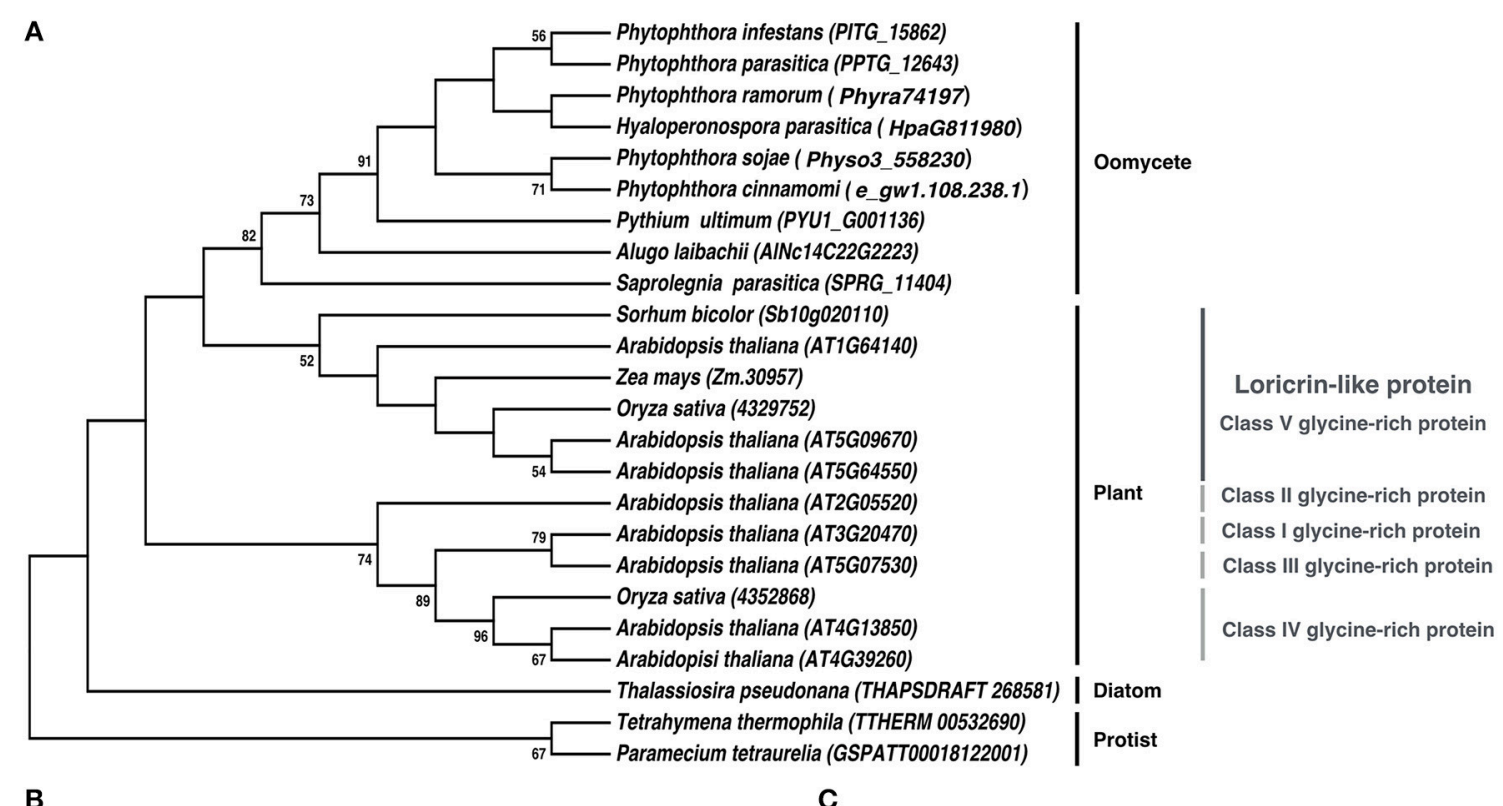

GGX/GXGX

MTVRTQYTNNGDYRNMHSLKVTATILT HLSTHATPALPGRHRPNPTRLPSIHSL

FTVDAAHAIAAVLPPLQCAVGLINLGT

PIGHHQSPVTSPAKPVVGSPTSPGMTP

VGPICQSDSTSATSVSISSKTRRPLSLH

DLLSTETTSTPSTQRCTNVHHRRQCGI

ADCQKYALTGGFCIRHGGGKRCNFE

GCQTVAQSGGRCKAHGGGSKCKVP

GCGSVARRKGFCMTHGGRQQCKVD

NCGKCAHGGGFCISHGGGKRCSSK

ACNKSAQAGGFCYSHGGGKRCAAP

ECFQAARKGGLCIRHRKLAAARCF
C

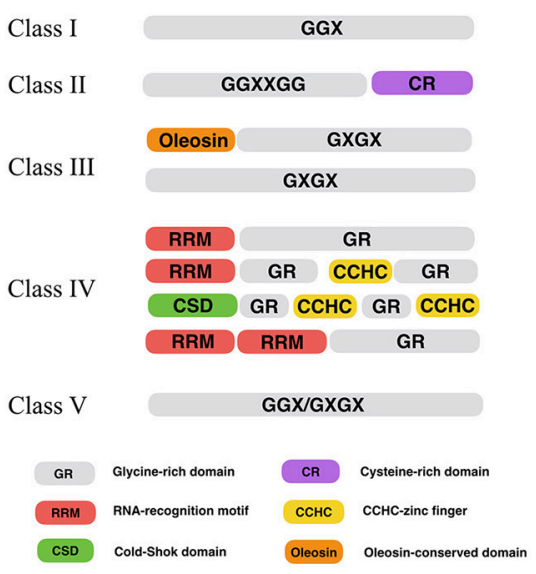

FIGURE 1 | Sequence analysis of PiLLP. (A) Phylogenetic analysis of LLP from different organisms. A maximum-likelihood tree was constructed using MEGA 5 with LLP sequences from the species including, Phytophthora cinannmomi, Phytophthora infestans, Phytophthora ramorum, Phytophthora sojae, Phytophthora parasitica, Albugo laibachii, Hyaloperonospora parasitica, Pythium ultimum, Saprolegnia parasitica, Thalassiosira pseudonana, Micromonas pusilla, Arabidopsis thaliana, Oryza sativa, Sorhum bicolor, Zea mays, Paramecium tetraurella, and Tetrahymena thermophile. Phylogenetic trees were constructed with the maximum likelihood evolution algorithm in MEGA 5.22. The statistical strengths were assessed by bootstraps with 1000 replicates. Bootstrap values ( $\geq 50 \%)$ are shown near the tree nodes. (B) The complete amino acid sequence of PiLLP (accession number XP_002898099). Orange bold letter, glycine repeat region. (C) Schematic representation of plant glycine-rich proteins classification. CCHC, CCHC-zinc finger; CSD, Cold-shock domain; CR, cysteine-rich domain; GR, Glycine rich domain; Oleosin, Oleosin-conserved domain; RRM, RNA-recognition motif. Glycine-rich repeats are indicated as GGX, GGXXXGG, GXGX, and GGX/GXGX, where G represents glycine and $X$ represents any amino acid (Modified from Mangeon et al., 2010).

viable immature oogonia, but others could not form oospores (Figure 5B). When the 11-day-old oogonia from STs, WT, and CK strains were observed by SEM, smooth oogonial walls appeared in the oogonia of WT and CK, whereas many sunken areas were observed on the surfaces of $\sim 50 \%$ of the oogonia of the STs, indicating the loss of turgor in these oogonia (Figure 5C).

A previous study showed that oogonia of Phytophthora went through the following three distinct stages during the oogonial expansion phase: (1) the oogonial wall thickens from 200 $\mathrm{nm}$ to $800 \mathrm{~nm}$; (2) the largely "functional" cytoplasm of the oogonium changes to vacuoles and lipid bodies by the time the oosphere is formed; (3) the oospore forms and the central ooplast is surrounded by a cortex of lipid bodies (Hemmes, 1983; Figure 5D). We stained the developing oogonia with Nile red to explore in which stage development is blocked. As shown in Figure 5E, the 7-day-old oogonia of STs exhibited the same phenotypes as those of the WT and the CK strains, emitting red fluorescence both in oogonia and in antheridia, indicating that lipid bodies were present in both. Almost all the 11-dayold oogonia of WT and CK showed red fluorescence only in oogonia, indicating that the lipid body in the antheridium is either degenerated or translocated into the oogonium, while 

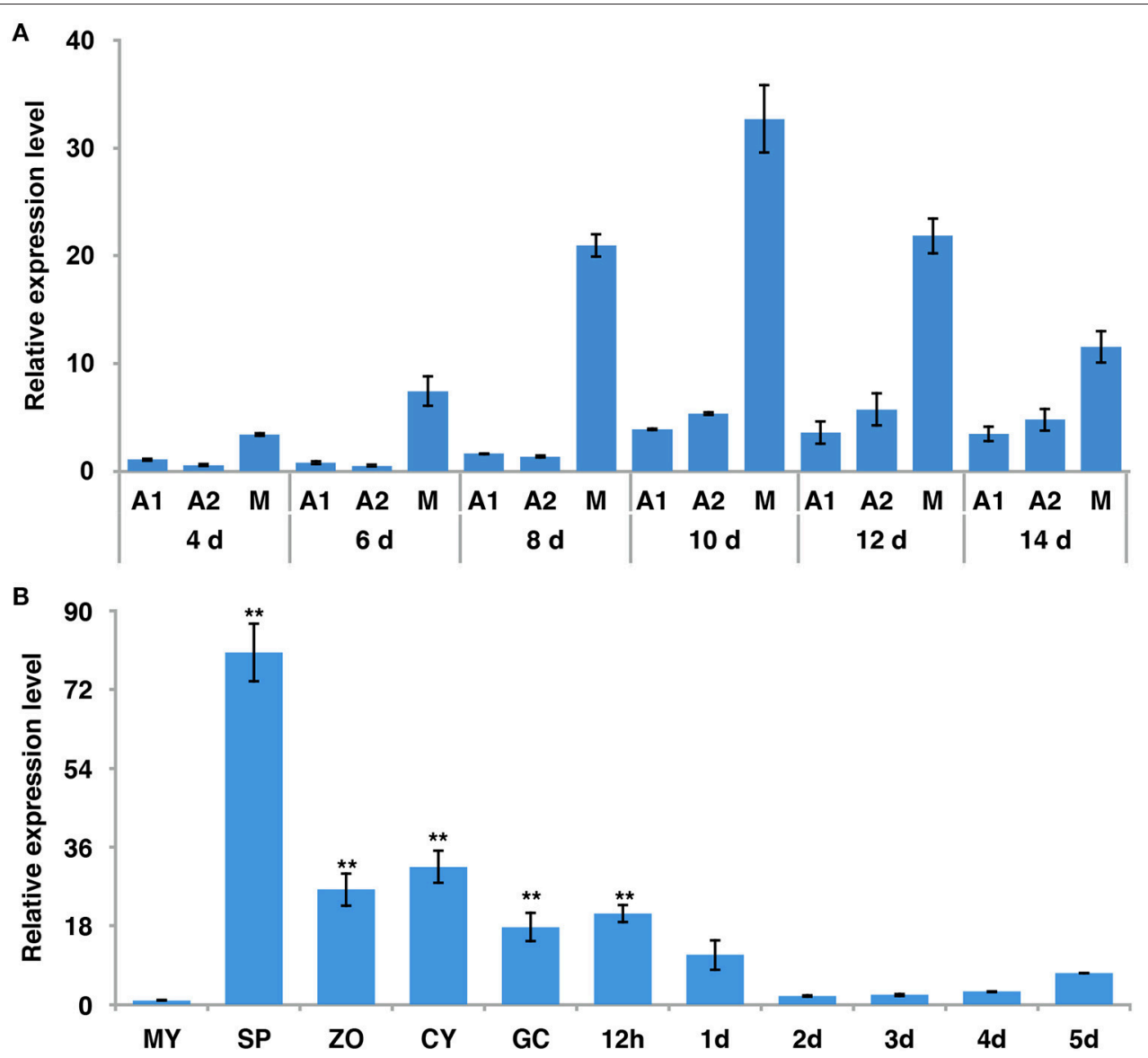

FIGURE 2 | The expression of PiLLP detected using qRT-PCR. (A) PiLLP expression in 4, 6, 8, 10, 12, and 14 days cultures with 4 days cultures of A1 mating type(MX5-1)as a reference (value, 1.0). (B) PiLLP expression in vegetative mycelia (MY), sporangia (SP), zoospores (ZO), cysts (CY), cyst germination (GC), and in the susceptible patato cv. Impala at different time course post-inoculation, in comparison to MY (value, 1.0). The elongation factor 1 (ef1) gene was used as an inner control. Three replicates were used for each treatment and the whole experiment was repeated with a different set of biological samples. Bars represent the standard deviation of three replicates. Statistical significance was analyzed using Student's $t$-test. Two asterisks indicate the significant difference $\left({ }^{\star \star} P<0.01\right)$.

the substance with red fluorescence was aggregated to form a "red ball." This kind of "red ball" was then observed in almost all of the oospores formed in the 17-day-old oogonia of WT and CK strains, while a little red fluorescence remained in the area between the wall of the oospore and the oogonium. However, nearly half of the 11-day-old oogonia of STs showed red fluorescence both in oogonia and in antheridia, and the red fluorescence-emitting substance was scattered instead of aggregating into a red ball (Figure 5E). In the 17-day-old oogonia of STs, no mature oospores were formed and only a small amount of red fluorescence-emitting substance was left in oogonia and antheridia (Figure 5E). Thus, the sexual development in STs is blocked in the stage of oospore wall formation.

\section{Asexual Phenotypes of PiLLP Transformants}

The colony diameters of STs (S3, S16, and S84) were significantly smaller than those of the WT and CK strains, whereas those of the OTs (O36 and O38) were not different from those of WT and CK, except that the mycelia of OTs colonies were denser (Figures 6A,B) $(P<0.01)$. In addition, the STs produced significantly less sporangia than the WT and CK strains (Figure 6C) $(P<0.01)$, and fewer zoospores were released from these sporangia in comparison with the WT and CK strains (Figure 6D). The OTs (O36 and O38) produced significantly more sporangia than WT and CK strains, and the number of zoospores released from these sporangia was almost equal to those of WT and CK strains (Figures 6C,D). In addition, the germination rates of the STs' sporangia were close to half the rates of WT and CK sporangia, whereas the germination rates of the OTs' sporangia were similar to those of the WT and CK strains (Figure 6E).

\section{Subcellular Localization of PiLLP in $P$. infestans}

In order to investigate the subcellular localization of PiLLP in $P$. infestans, we labeled PiLLP by fusing PiLLP with the gene encoding monomeric red fluorescent protein (mRFP) to 


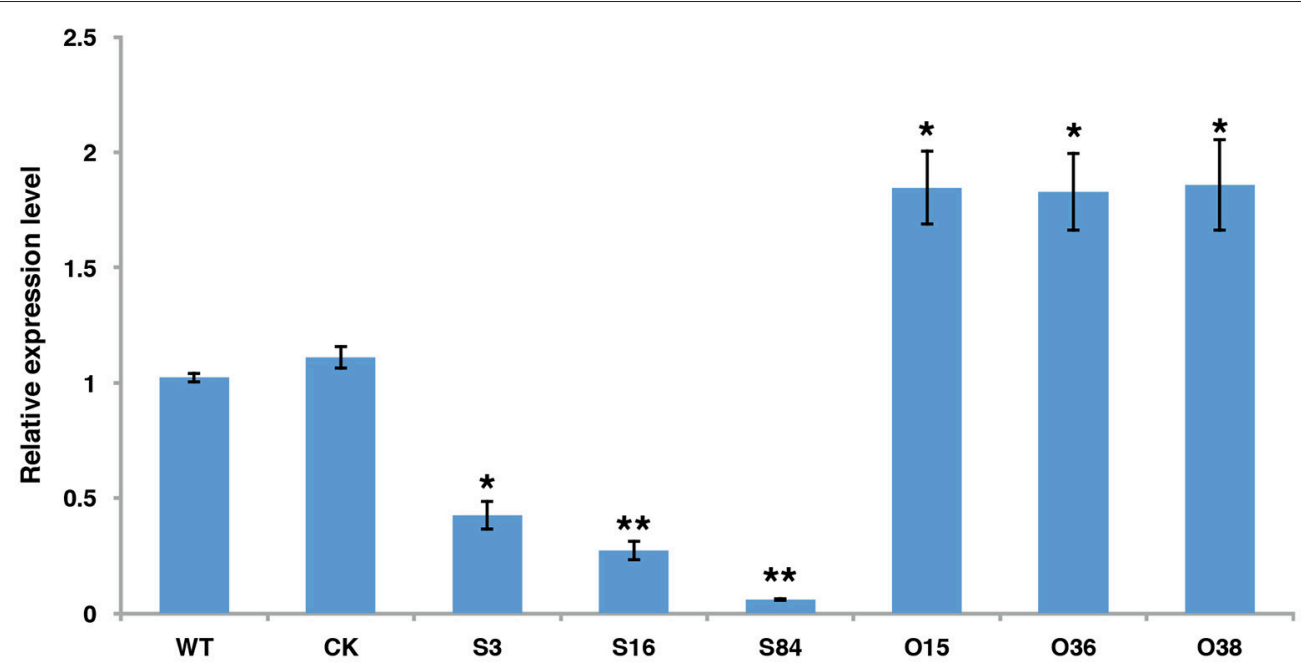

FIGURE 3 | The expression levels of PiLLP in WT, CK, and the PiLLP transformants (S3, S16, S84, O15, O36, and O38). qRT-PCR assay was performed using cDNAs synthesized from mycelial RNAs of different isolates. The level of PiLLP expression was determined relative to that of ef1, and WT was used as a reference (value, 1.0). Three replicates were used for each treatment and the whole experiment was repeated with a different set of biological samples. Bars represent the standard deviation of three replicates. Statistical significance was analyzed using Student's $t$-test between WT and each transformant $\left({ }^{\star} P<0.05\right.$, $\left.{ }^{\star \star} P<0.01\right)$.

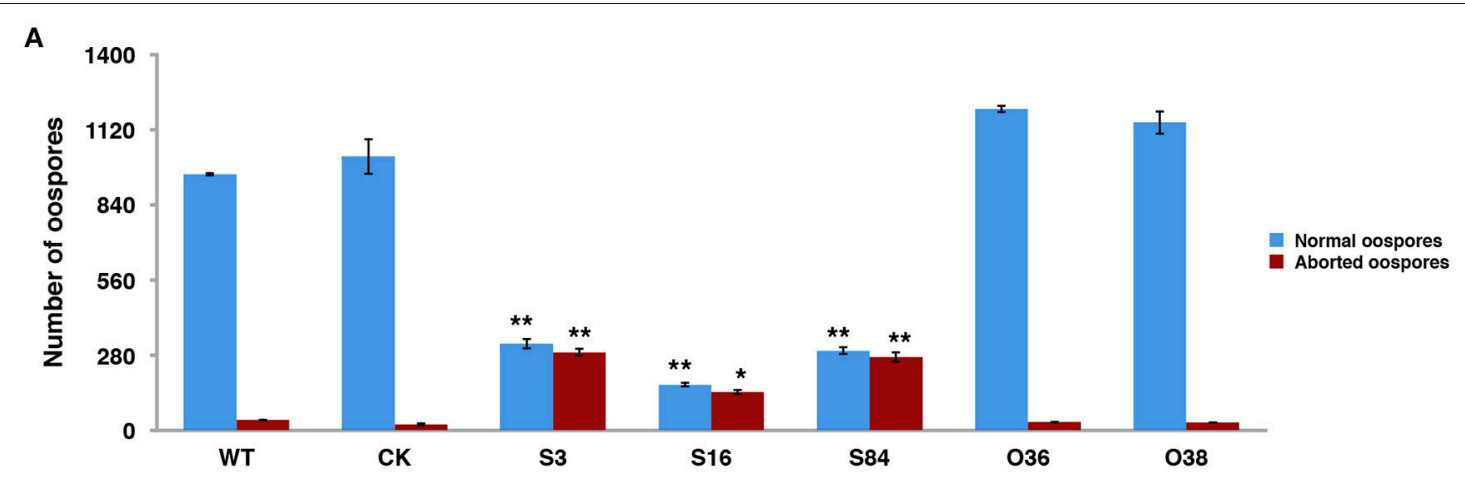

B
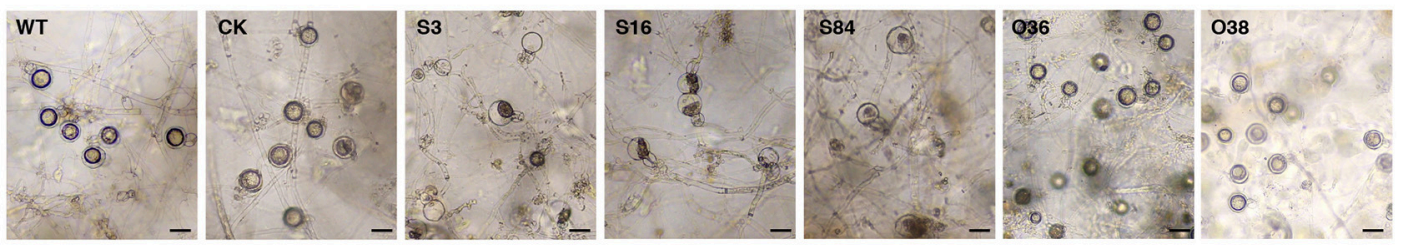

FIGURE 4 | PiLLP-silenced transformants produced many aborted oospores. (A) Amount of normal and aborted oospores produced by wild-type (WT), control strain (CK, carrying the empty vector of pToRmRFP4), and the PiLLP-silenced transformants (S3, S16, and S84). (B) Morphology of oospores produced in 17 days old cultures of WT, CK, and PiLLP-silenced transformants (S3, S16, and S84). The bars indicate $20 \mu \mathrm{m} .{ }^{\star} P<0.05,{ }^{\star \star} P<0.01$.

investigate the subcellular localization of the PiLLP protein in $P$. infestans. In asexual stages, the red fluorescence was observed in the cytoplasm of mycelia, sporangia, cysts, and germinated cysts. This fluorescence pattern was the same in the control strain $\mathrm{CK}$ and in three OT strains and therefore it is not possible to draw conclusions about the localization of PiLLP during asexual development. In the sexual stage, the fluorescence pattern in the three OT strains was different from the pattern seen in the CK strain. In the OT strains, the red fluorescence was specifically associated with the wall of the oogonia (Figure 7), indicating that PiLLP was localized in the oogonial walls.

\section{PiLLP Participates in Oxidative-Stress Resistance}

To determine whether PiLLP is an oxidative-associated gene, the PiLLP expression levels in cultures treated with various 


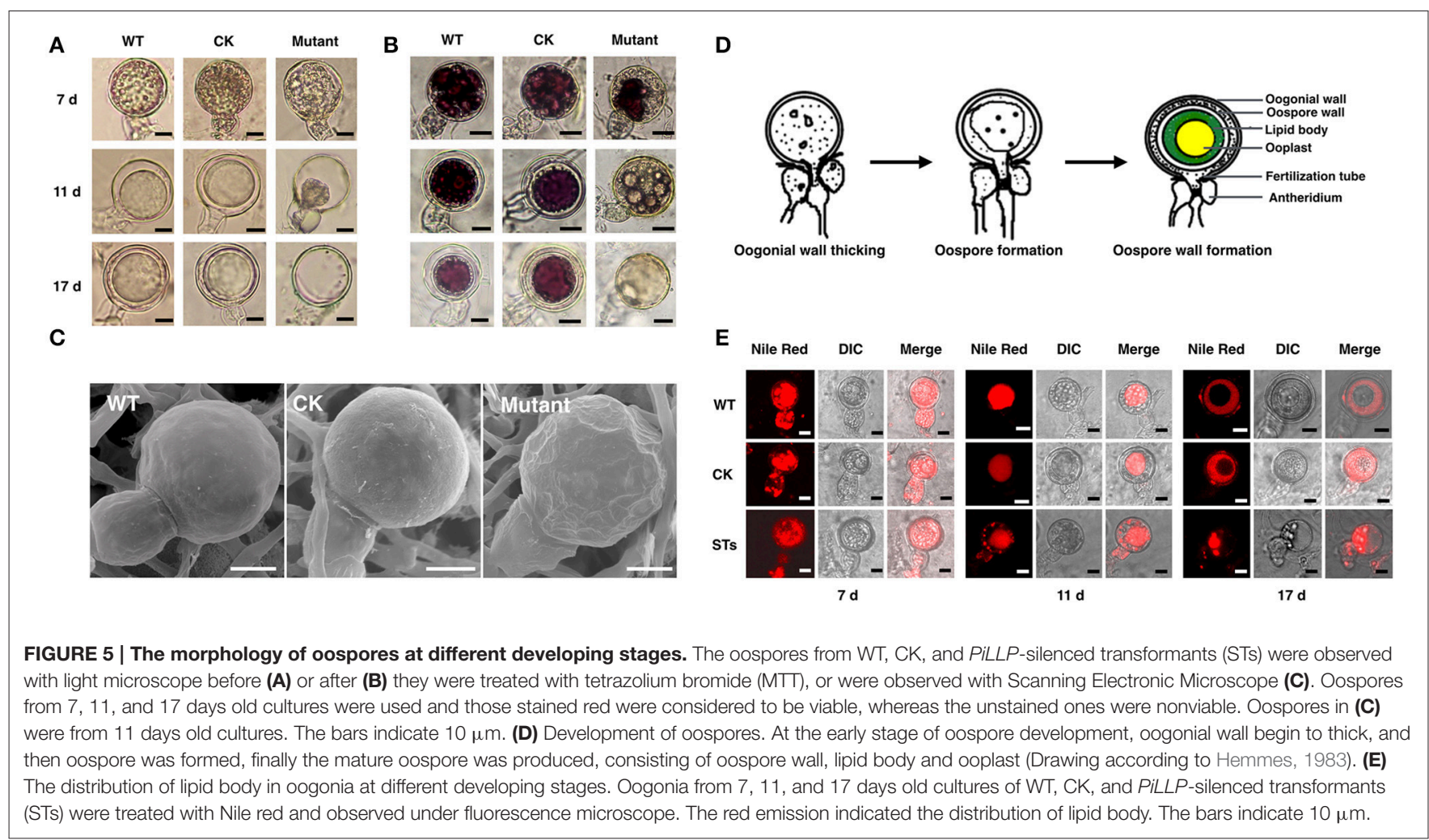

concentration of $\mathrm{H}_{2} \mathrm{O}_{2}$ were investigated. The expression of PiLLP in the WT strain increased with increased $\mathrm{H}_{2} \mathrm{O}_{2}$ concentrations in the medium and was $\sim 10$-fold greater when the $\mathrm{H}_{2} \mathrm{O}_{2}$ concentration reached $2.0 \mathrm{mM}$ (Figure 8A; Table S4). The growth rates of STs decreased greatly at $0.5,1.0,1.5$, and $2.0 \mathrm{mM} \mathrm{H}_{2} \mathrm{O}_{2}$, and completely ceased at $2.0 \mathrm{mM} \mathrm{H}_{2} \mathrm{O}_{2}$. The inhibition rate of $\mathrm{H}_{2} \mathrm{O}_{2}$ on OTs growth was consistent with those of WT and CK strains (Figures 8B,C).

\section{PiLLP Silencing Reduces the Virulence of $P$. infestans}

To determine whether PiLLP is required for $P$. infestans pathogenicity, the detached leaves of potato ( $\mathrm{cv}$. Impala) were inoculated with equivalent amounts of germinated WT, CK, ST (S3, S16, and S84), and OT (O36 and O38) sporangia, independently. At 5 days post-inoculation, the typical disease symptoms of water-soaked lesions were observed on the leaves inoculated with WT, CK, and OTs (O36 and O38) strains, except that more aerial mycelia were observed on lesions induced by OTs. In contrast, only small brown spots were induced by the ST strains (Figures 9A-C). As the plant-derived ROS is an important defense mechanism of protecting plant from microorganism invasion, we pretreated the detached leaves with diphenyleneiodium (DPI), a flavoenzyme inhibitor that prevents the activation of NADPH oxidases, before inoculating with the STs. The lesion sizes on these treated leaves increased to half size of that induced by WT and were twice as large as those on the DPI-untreated leaves (Figures 10A,D). More mycelia were observed in cells at the inoculation site than in those of
DPI-untreated leaves inoculated with STs (Figure 10B), and less reddish-brown precipitate was observed in the infection site of STs in DPI-treated leaves (Figure 10C). For leaves inoculated with OTs, no significant increase in lesions size was observed on DPI-treated leaves (Figure 10D). We observed the less dense of mycelia on lesions and in tissues at inoculation site treated with DPI or DMSO, and a lighter brown color in the infection site in DPI-treated leaves (Figures 10A-C). This finding indicates that the pathogenicity of STs could be partially restored by DPI treatment.

\section{PiLLP Silencing Reduces Catalase Genes Expression Level and Catalase Activities}

As the transcriptome analysis of $P$. infestans showed the upregulation of two catalase genes, (PITG_15248 and PITG_07143) during the early infection stages (Haas et al., 2009), we then analyzed the expression level of these genes in WT, CK, and transformants. The expression levels of these two genes were significantly decreased in STs, whereas the expression level of PITG_15248 was significantly increased in OTs, compared with those in WT and CK (Figure 11A; Table S4). We then further investigated the activity of catalases of WT, CK, and transformants by analyzing the total catalase activities of the crude proteins extracts from these isolates with PAGE under nondenatured conditions (Figure 11B). As shown in Figure 11B, the bands of WT and CK strains were thicker and brighter than those of STs, but significantly lighter and thinner than those of OTs, indicating the decrease of catalase activity in STs and the increase of catalase activity in OTs. 

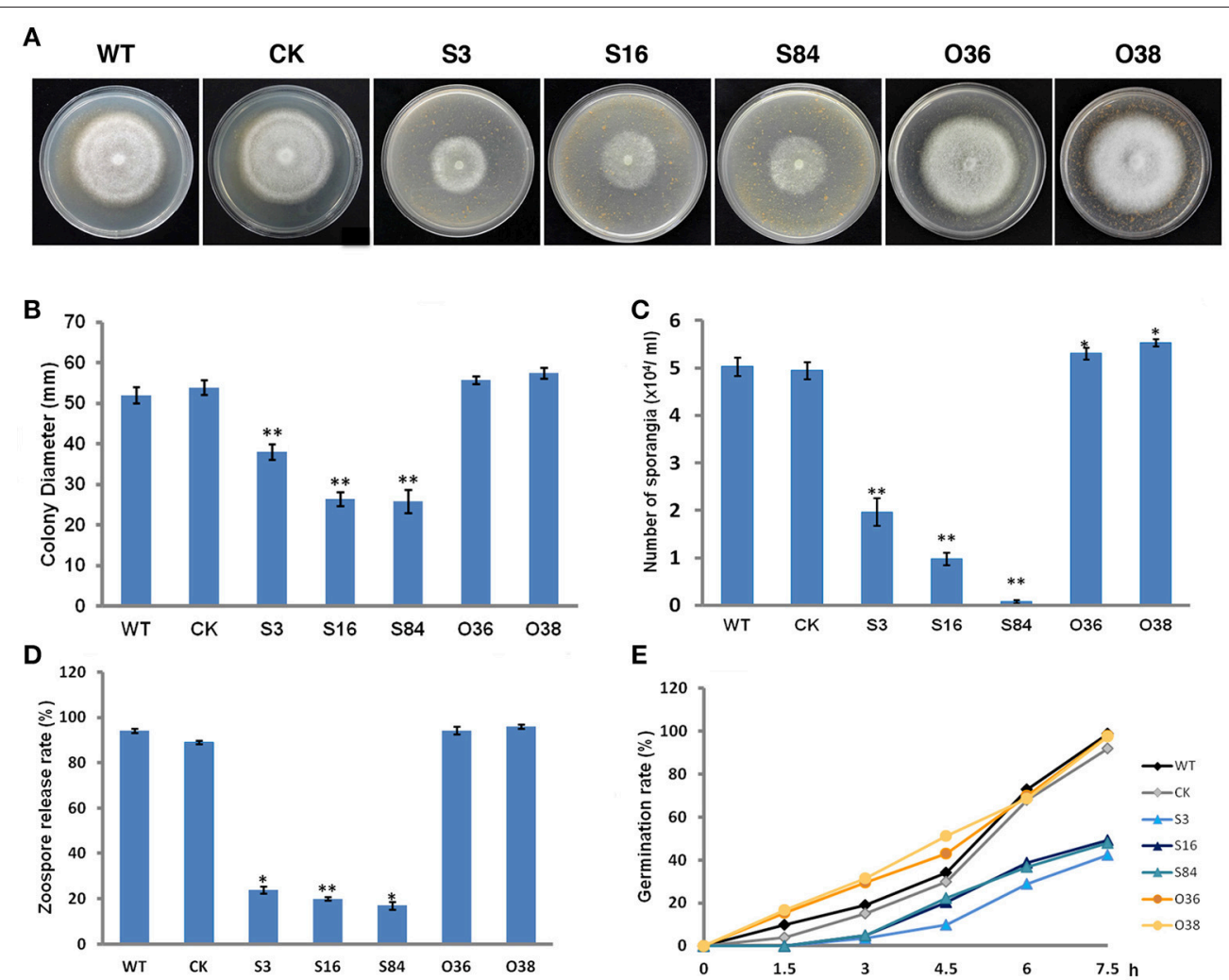

FIGURE 6 | Asexual phenotype characterization. (A) Growth of the WT, CK, and the PiLLP transformants (S3, S16, S84, O36, and O38). Photos were taken at 7 days after incubation on 10\% TRA medium. (B) Statistics of colony diameters was based on 7 days of growth on 10\% TRA medium. (C) Sporangia of the WT, CK, and the PiLLP transformants (S3, S16, S84, O36, and O38) formed on 10 days old cultures were washed with water and then counted under the microscope. (D) Sporangia suspension was incubated in a plate for $2 \mathrm{~h}$ at $4^{\circ} \mathrm{C}$. The ratios of the number of empty sporangia to the total number of sporangia were calculated for each strain. (E) Sporangia suspension was incubated in $200 \mathrm{~g} / \mathrm{L}$ Peabroth at $18^{\circ} \mathrm{C}$. The numbers of germinated and un-germinated sporangia were counted under a microscope at different time points $(0,1.5,3,4.5,6$, and $7.5 \mathrm{~h})$, and the percentage of the germinated sporangia to the total number of sporangia were calculated for each strain. Three replicates were used for each treatment and the whole experiment was repeated once with three replicates. Bars represent the standard deviation of three replicates. Statistical significance was analyzed with Student's $t$-test between WT and each transformant $\left({ }^{\star} P<0.05,{ }^{* \star} P<0.01\right)$.

\section{DISCUSSION}

\section{LLP Is Required in the Reproduction of Oomycetes}

In this study, we identified a $P$. infestans ortholog of the plant LLP gene. Bioinformatics analysis showed that LLP is highly conserved in oomycetes and contains mixed GGX and GX repeats. The protein is phylogenetically related to the LLP, Class V GRPs in plants, which function is not clear. The similarity between PiLLP and the rest of LLPs ranged from 32.1 to $90.9 \%$. In animals and humans, loricrin is a highly insoluble structural protein and is the main component of the cornified cell envelope, which functions as structural reinforcement (Kalinin et al., 2001). Together with the indication of its localization in oogonial walls, this suggests that LLP is a structural component in the ooginial wall. The increase in PiLLP expression in asexual and sexual development stages also indicates that PiLLP is required for reproduction of $P$. infestans. Thus, the decrease in the colony expansion rate, the formation rates of sporangia and oospores, and the zoospore-releasing rate in PiLLP-silenced transformants is not surprising. However, further investigation is needed to confirm its localization on oogonia wall.

\section{PiLLP Is Involved in Oospore Formation}

Previous studies showed that various types of proteins constitute $12.5 \%$ of the oospore-oogonium wall, and the most abundant amino acid residue in these proteins is glycine followed by alanine, arginine, aspartic acid, and glutamic acid (Lippman et al., 1974), which is consistent with the amino acid composition of PiLLP. The presence of layered patches of electron-dense deposits at the inner layer of oogonial wall likely belong to osmiophilic proteins or lipids, but these layered patches of electron-dense deposits are absent in the walls of hyphae, sporangia, zoospores, and cysts (Hegnauer and Hohl, 1978).

Here, some STs could form many normal immature oogonia but $\sim 45 \%$ of these oogonia could not form oospores. The simultaneous loss of lipid bodies and turgor in the oogonia indicates that the loss of cytoplasm content and/or turgor is related to defective oospore formation in the STs. Previous studies on the gametangial development in Phytophthora spp. showed that fertilization occurs before oosphere formation, and 


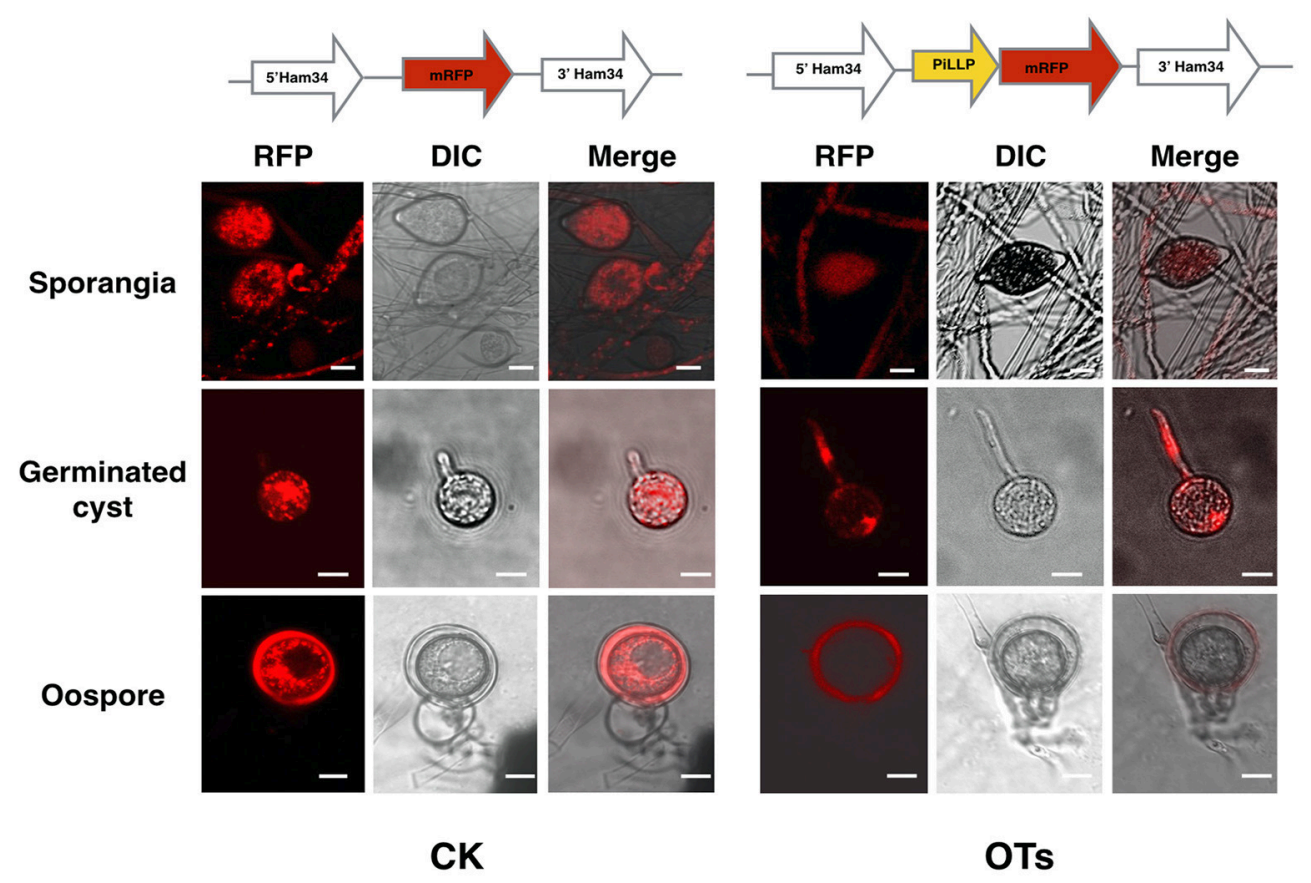

FIGURE 7 | Subcellular localization of PiLLP in oospores. The red fluorescence was present in the cytoplasm of mycelia, sporangia, cysts and germinated cysts of control (CK) and the PiLLP-overexpressed transformants (OTs), but it was limited to the oogonium wall of OTs. The bars indicate $10 \mu \mathrm{m}$.

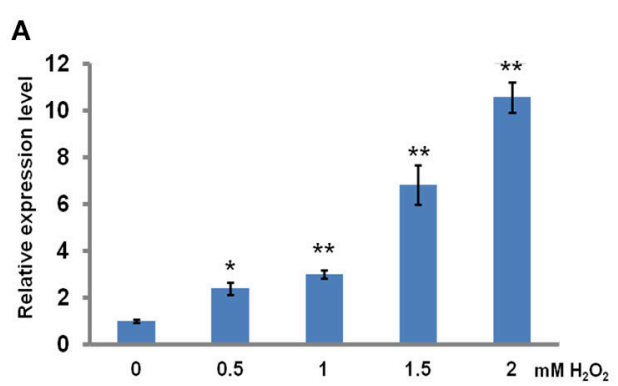

B

C
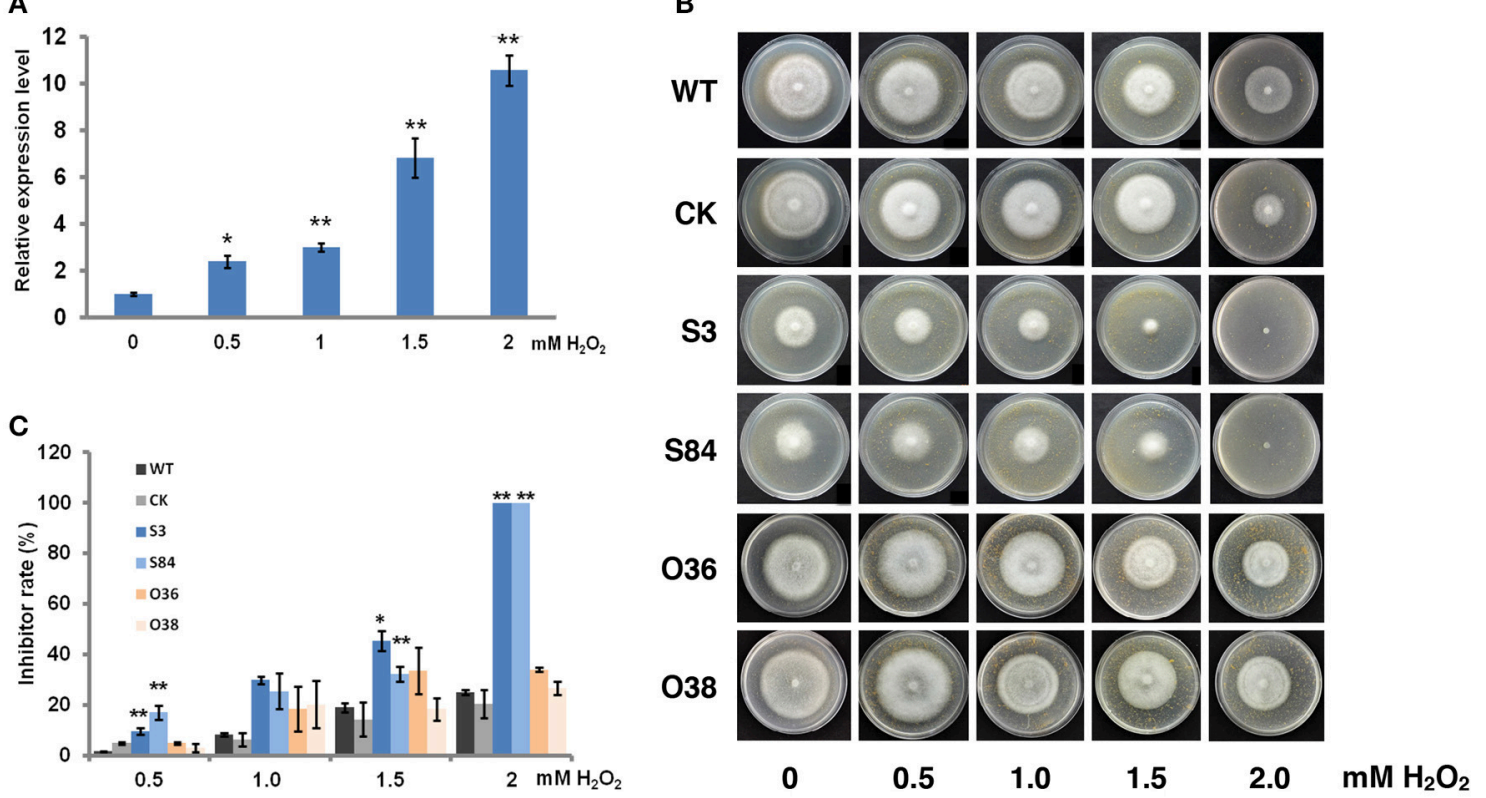

FIGURE 8 | PiLLP participates in the response to oxidative stress. (A) Levels of PiLLP expression in mycelia grown on medium amended with various concentration of hydrogen peroxide $\left(\mathrm{H}_{2} \mathrm{O}_{2}\right)$. The qRT-PCR assay was performed using cDNAs synthesized from mycelial RNAs. The level of PiLLP expression was determined relative to that of ef1, and the relative gene expression levels shown were determined relative to expression on TRA medium alone (value, 1.0). (B) Colony expansion of WT, CK, and PiLLP transformants (S3, S84, O36, and O38) on TRA medium supplemented with 0, 0.5, 1.0, 1.5, and 2.0 mM H $\mathrm{H}_{2}$. (C) Colony diameters were measured after 7 days of growth. Rates of growth inhibition were calculated for each isolates of each treatment relative to the growth on TRA medium. Three replicates were used for each treatment in these tests and the whole experiment was repeated once. Bars represent the standard deviation of three replicates. Statistical significance was analyzed using Student's $t$-test between WT and each transformant $\left({ }^{\star} P<0.05,{ }^{\star \star} P<0.01\right)$. 


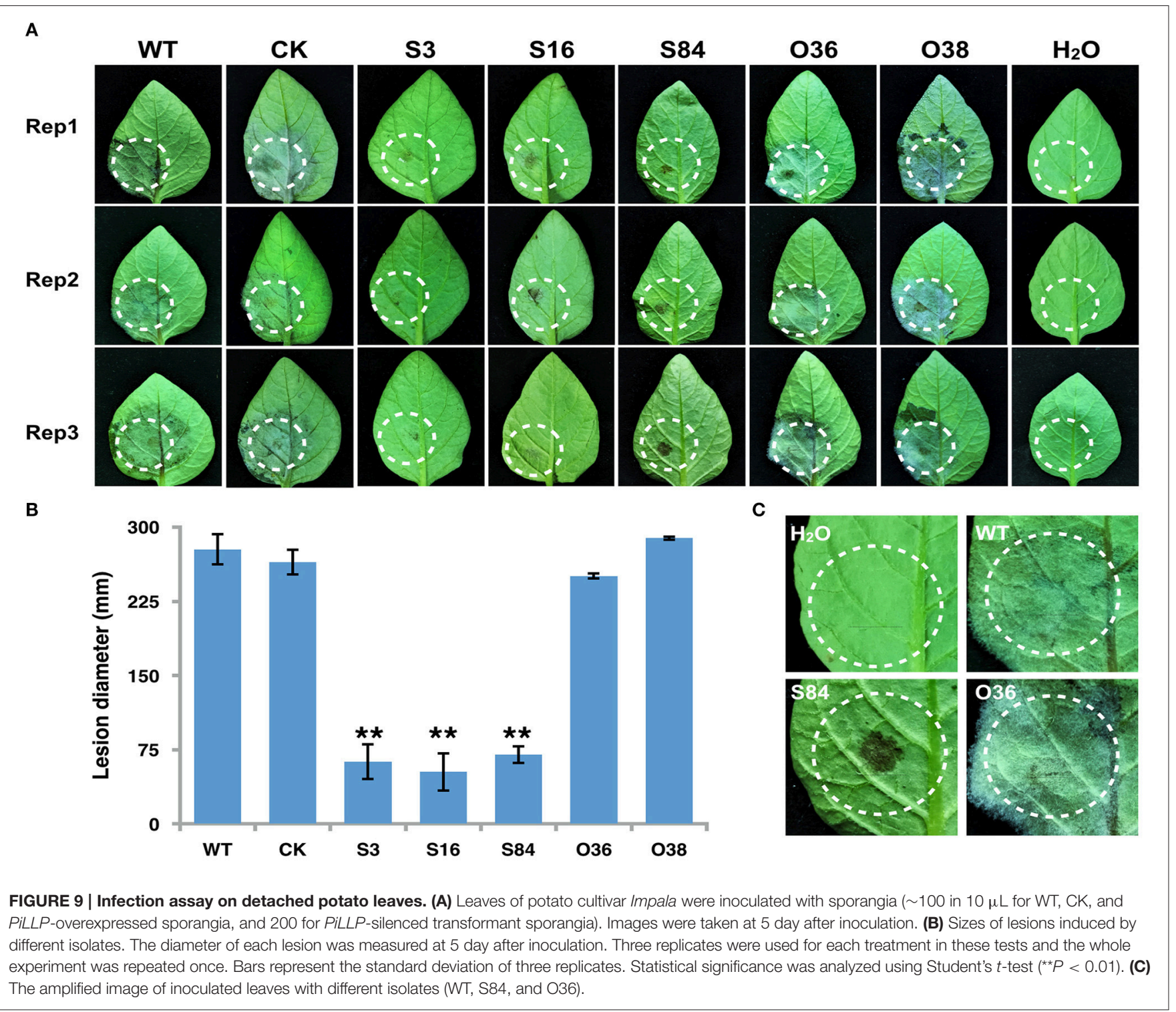

the antheridial nucleus enters oogonia through the fertilization tube, rupturing the oogonial wall (Figure 5D; Hemmes and Bartnicki-Garcia, 1975; Hemmes and Ribeiro, 1977). As a consequence, the ruptured area on the oogonial wall requires patching to avoid leaking cytoplasm and nuclei from oogonium. However, the shortage of structural proteins in the oogonial wall may result in an unpatched oogonial wall break, ultimately leading to the failure of oospore formation. The Nile red staining of developing sexual apparatus provided evidence supporting this speculation. As shown, the red fluorescence-emitting substance indicated that the lipid bodies were present only in antheridia attached to the 17-day-old (late stage) partially emptied oogonia from STs, not in those attached to the oogonia with mature oospores, indicating the translocation of lipid bodies from the later stage oogonium to the antheridium (Figure 5E).

Thus, this study suggested that PiLLP is a structural component of the oogonial wall and is likely related to the electron-dense deposits specific to the oogonial wall. However, further investigations are needed to illustrate the components of the electron-dense deposits on the inner oogonial wall. Previously, a small tyrosine rich protein, PoStr, was shown to be involved in the oogonial and oospore wall formation in Phythium sp. (Grenville-Briggs et al., 2013).

\section{PiLLP Is Involved in Scavenging Plant ROS}

The accumulation of plant-derived ROS at the infection site is an early immunity response in plants (Mellersh et al., 2002; Torres and Dangl, 2005). To successfully invade plant cells, plant pathogens must avoid damage from ROS through self-protection or scavenging ROS, or both. In plant fungal pathogens, several genes, such as Yap1 in Ustilago maydis (Molina and Kahmann, 2007) and DES1 in Magnaporthe oryzae (Chi et al., 2009) are responsible for ROS detoxification at the infection site and are required for virulence. 

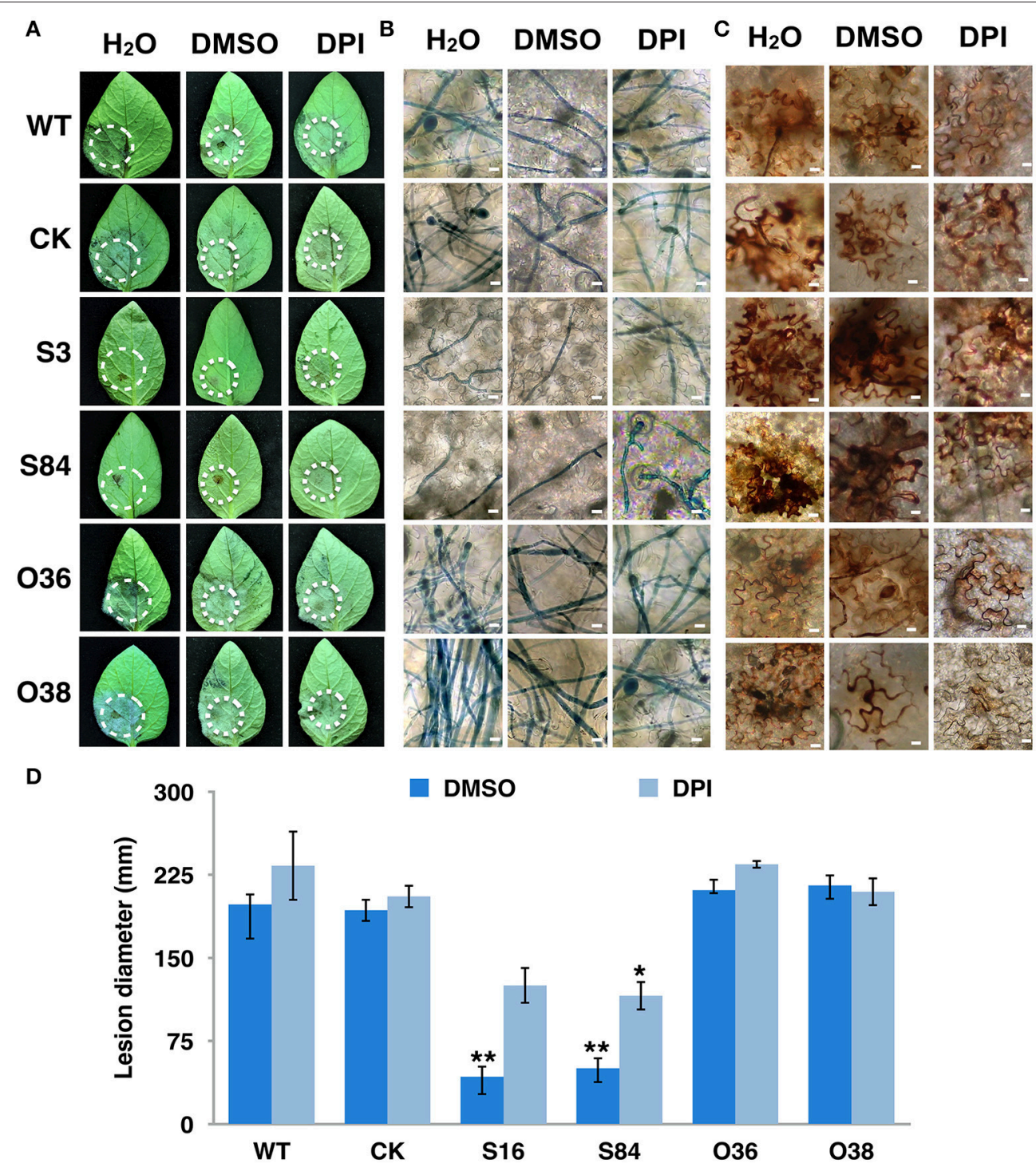

FIGURE 10 | Virulence of PiLLP-silenced transformants restored by DPI treatment. (A) Disease lesions induced by different isolates. Detached leaves of potato cultivar Impala were injected with $\mathrm{H}_{2} \mathrm{O}, 0.05 \% \mathrm{DMSO}$ and $0.5 \mu \mathrm{M} \mathrm{DPI}$. The treated leaves were inoculated on injection sites with sporangia [ 100 in $10 \mu \mathrm{L}$ for WT, CK, and PiLLP-overexpressed sporangia, whereas 200 for PiLLP-silenced transformant sporangia]. Pictures were taken 5 day after inoculation. (B) Microscopic observations of invasive hyphae in potato leave. The inoculated leaves were boiled for $\sim 2 \mathrm{~min}$ in lactophenol-trypan blue and decolorized in $2.5 \mathrm{~g} / \mathrm{ml}$ chloral hydrate for 30-40 min. (C) Detached leaves of $\mathrm{N}$. benthamiana were injected with $\mathrm{H}_{2} \mathrm{O}, 0.05 \%$ DMSO and $0.5 \mu \mathrm{M} \mathrm{DPI}$ and then inoculated with sporangia of WT, CK, and PiLLP transformants. Twelve hours after inoculation, the leaves were incubated in $1 \mathrm{mg} / \mathrm{mL} \mathrm{DAB}$ solution $(\mathrm{pH} 3.8)$, at room temperature for $8 \mathrm{~h}$ and destained with ethanol, and observed with a microscope. The bars indicate $10 \mu \mathrm{m}$. (D) Lesion diameter on DPI-untreated and -treated leaves induced by different isolates. The diameter of each lesion was measured at 5-day after inoculation. Three replicates were used for each treatment and the whole experiment was repeated once. Bars represent the standard deviation of three replicates. Statistical significance was analyzed using Student's $t$-test. The asterisk indicates the significant difference $\left({ }^{*} P<\right.$ $\left.0.05,{ }^{\star \star} P<0.01\right)$. Two independent infection assays were performed with similar results.

STs being more sensitive to $\mathrm{H}_{2} \mathrm{O}_{2}$ than the WT and OTs strains, and the induced expression of PiLLP in the WT strain being highly increased as the $\mathrm{H}_{2} \mathrm{O}_{2}$ concentration increased in the medium, indicated that $P i L L P$ is involved in resistance to $\mathrm{H}_{2} \mathrm{O}_{2}$. Additionally, a greater amount of $\mathrm{H}_{2} \mathrm{O}_{2}$ accumulation and a decline in mycelial expansion occurred in infection site tissues inoculated with STs than in those inoculated with WT, $\mathrm{CK}$, and OTs. We also showed that the reduced pathogenicity of the STs could be partially restored with DPI treatments. These results indicate that the expansion of STs in infection site tissues is limited partially because of the attack of hostderived ROS. Therefore, we speculate that PiLLP is involved in scavenging plant ROS during infection. A transcriptome analysis of $P$. infestans revealed that two catalase genes (PITG_15248 and PITG_07143) were up-regulated during early infection stages (Haas et al., 2009). Here, we found that the expression levels of 

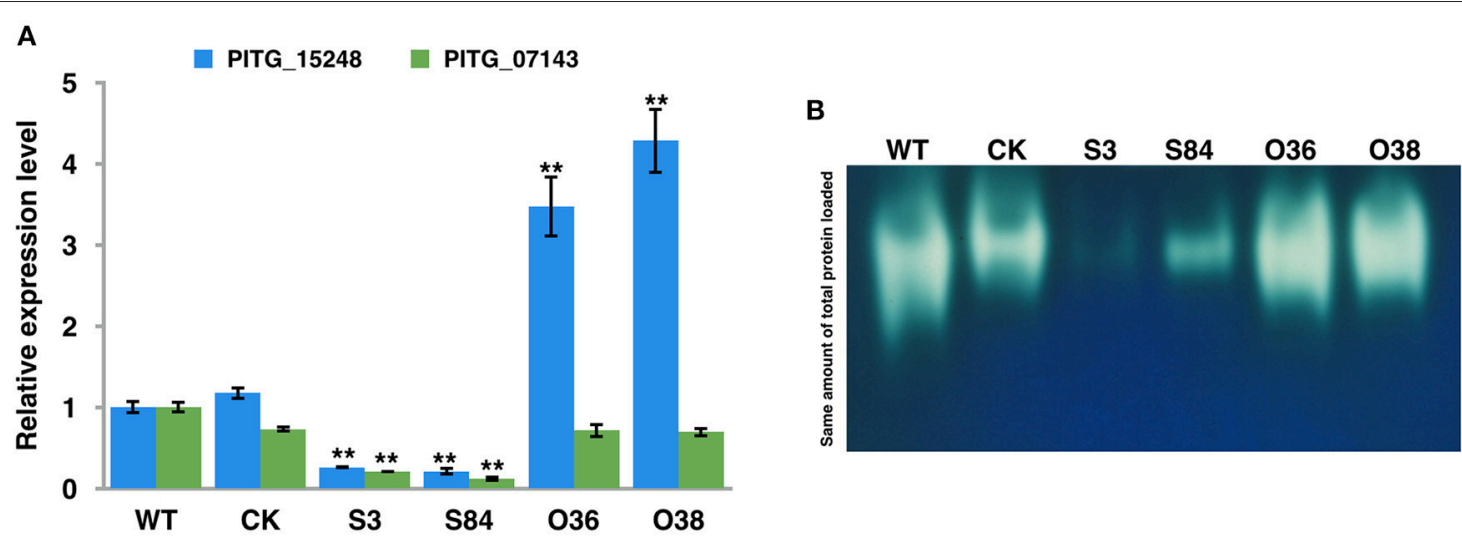

FIGURE 11 | PiLLP-silenced transformants with reduced catalase genes expression level and lower catalase activities. (A) The expression levels of two catalase genes (PITG_15248 and PITG_07143) in WT, CK, and transformants (S3, S84, O36, and O38). The qRT-PCR assay was performed using cDNAs synthesized from mycelial RNAs of different isolates (WT, CK, STs and OTs). The levels of PITG_15248 or PITG_07143 were determined relative to that of ef1, and the expression level of WT was used as a reference (value, 1.0). (B) In-gel assay of catalase activity. Equal amounts of total protein (20 $\mu \mathrm{g})$ of different isolates (WT, CK, STs, and OTs) were loaded into Native-PAGE. The gel was immersed in $7 \mathrm{mM} \mathrm{H}_{2} \mathrm{O}_{2}$ for 10 min after electrophoresis, and then incubated in a $1 / 1$ mixture of freshly prepared $1 \%$ potassium hexacyanoferrate (III) and $1 \%$ iron (III) chloride hexahydrate. Blue color was observed in the gel except at zones where $\mathrm{H}_{2} \mathrm{O}_{2}$ was decomposed by catalases. Three replicates were used for each treatment in these tests and the whole experiment was repeated with a different set of biological samples. Bars represent the standard deviation of three replicates. Statistical significance was analyzed using Student's $t$-test between WT and each transformant (** $P<0.01$ ).

these two genes were decreased in STs compared with those in WT, CK, and OTs. We further investigated the activity of catalase in different isolates and found the decrease of catalase activity in STs and the increase of catalase activity in OTs compared with WT and CK. These results suggested that PiLLP affected the pathogenicity of isolates through affecting the catalase activity, which is important for scavenging plant ROS.

In the pathogenicity test, we placed a double amount of STs sporangia on the leaves to compensate for the lower germination rate of STs sporangia, which was around $50 \%$ of the WT and OTs. The growth rates of the two STs used in the pathogenicity test were about $50 \%$ lower than those of WT and OTs. Thus the defect in growth rate of STs may explain why pathogenicity of STs was not fully restored by DPI treatment. In P. infestans, two homologous genes of PiLLP were detected, and the expression of two genes with high sequence identities to PiLLP (PITG_10076, 51.1\%; PITG_00234, 46.8\%) in WT and STs did not show significant difference (Table S5).

Sequence analysis revealed that PiLLP does not contain a signal peptide or any structural domain with known functions but does contain a number of mixed GGX/GXGX repeats. Therefore, it is less likely that PiLLP could function as a secreted effector inducing plant cell death or as a cell wall-degrading enzyme. So, it is reasonable that the overexpression of this gene didn't increase the virulence of the OTs. DPI is a flavoenzyme inhibitor that can scavenge the host-derived ROS. As the pathogenicity test showed that WT, CK, and OTs can scavenge the host-derived ROS by itself, but not STs, it is expected that DPI treatment experiments have an obvious effect only on STs, but not on OTs.

Previous work suggested that the heat shock transcription factor PsHSF1 and histone acetyltransferase PsGcn5 were involved in oxidative stress responses and detoxifying oxidative bursts (Sheng et al., 2015; Zhao et al., 2015). Our study showed that PiLLP is involved in the $\mathrm{H}_{2} \mathrm{O}_{2}$ resistance and ROS scavenging, which are likely caused by affecting the transcription level of catalase genes. Previous research has shown the diverse functions of the GRPs in plants, but the function of the glycine-rich repeats in these proteins is not known (Mangeon et al., 2010). One speculation is that the glycinerich repeats are necessary for interaction with other proteins in a multicomponent complex (Mangeon et al., 2010). However, further studies are expected to resolve the detailed mechanisms involved.

\section{AUTHOR CONTRIBUTIONS}

Conceived and designed the study: LG Performed the experiment: TG Participate in some experiments: $\mathrm{XW}$ and KS. Edited and contributed to the manuscript: TG, XW, WS, and LG. All authors read and approved the final manuscript.

\section{FUNDING}

This research was funded in part by the National Natural Science Foundation of China (30270862) and the Chinese Universities Scientific Fund (2015NX005).

\section{ACKNOWLEDGMENTS}

We sincerely thank Yuan chao Wang (Nanjing Agricultural University) and Francine Govers (Wageningen University) for providing the vector pTORmRFP4. 


\section{SUPPLEMENTARY MATERIAL}

The Supplementary Material for this article can be found online at: http://journal.frontiersin.org/article/10.3389/fpls.2017. 00142/full\#supplementary-material

Table S1 | The LLP genes of $\boldsymbol{P}$. infestans and other species.
Table S2 | Primers used for all experiments.

Table S3 | Percentage of aborted oospores of WT, CK, and transformants.

Table S4 | Gene expression data of qRT-PCR in this study.

Table S5 | Expression level of PITG_10076 and PITG_00234.

\section{REFERENCES}

Adl, S. M., Simpson, A. G., Farmer, M. A., Andersen, R. A., Anderson, O. R., Barta, J. R., et al. (2005). The new higher level classification of eukaryotes with emphasis on the taxonomy of protists. J. Eukaryot. Microbiol. 52, 399-451. doi: 10.1111/j.1550-7408.2005.00053.x

Apel, K., and Hirt, H. (2004). Reactive oxygen species: metabolism, oxidative stress, and signal transduction. Annu. Rev. Plant Biol. 55, 373-399. doi: 10.1146/annurev.arplant.55.031903.141701

Apostol, I., Heinstein, P. F., and Low, P. S. (1989). Rapid stimulation of an oxidative burst during elicitation of cultured plant cells: role in defense and signal transduction. Plant Physiol. 90, 109-116. doi: 10.1104/pp.90.1.109

Aylor, D. E., Fry, W. E., Mayton, H., and Andrade-Piedra, J. (2001). Quantifying the rate of release and escape of Phytophthora infestans sporangia from a potato canopy. Phytopathology 91, 1189-1196. doi: 10.1094/PHYTO.2001.91.12.1189

Baldauf, S. L., Roger, A. J., Wenk-Siefert, I., and Doolittle, W. F. (2000). A kingdom-level phylogeny of eukaryotes based on combined protein data. Science 5493, 972-977. doi: 10.1126/science.290.5493.972

Bocca, S. N., Magioli, C., Mangeon, A., Junqueira, R. M., Cardeal, V., Margis, R., et al. (2005). Survey of glycine-rich proteins (GRPs) in the Eucalyptus expressed sequence tag database (ForEST). Genet. Mol. Biol. 28, 608-624. doi: 10.1590/S1415-47572005000400016

Bourke, A. (1993). "The visitation of God"? The potato and the Great Irish Famine. Dublin: The Lillput Press.

Brouwer, H., Coutinho, P. M., Henrissat, B., and de Vries, R. P. (2014). Carbohydrate-related enzymes of important Phytophthora plant Pathogens. Fungal Genet. Bio. 72, 192-200. doi: 10.1016/j.fgb.2014.08.011

Cassab, G. I. (1998). Plant cell wall proteins. Annu. Rev. Plant Physiol. Plant Mol. Biol. 49, 281-309. doi: 10.1146/annurev.arplant.49.1.281

Chi, M. H., Park, S. Y., Kim, S., and Lee, Y. H. (2009). A Novel pathogenicity gene is required in the rice blast fungus to suppress the basal defenses of the host. PLoS Pathog. 5:e1000401. doi: 10.1371/journal.ppat.1000401

Cross, A. R., and Jones, O. T. G. (1986). The effect of the inhibitor diphenylene iodonium on the superoxide-generating system of neutrophils. Biochem. J. 237, 111-116. doi: 10.1042/bj2370111

de Oliveira, D. E., Franco, L. O., Simoens, C., Seurinck, J., Coppitiers, J., Botterman, J., et al. (1993). Inflorescence-specific genes from Arabidopsis thaliana encoding glycine-rich proteins. Plant J. 3, 495-507. doi: 10.1046/j.1365-313X.1993.03040495.x

Doke, N., Miura, Y., Sanchez, L., Park, H., Noritake, T., Yoshioka, H., et al. (1996). The oxidative burst protects plants against pathogen attack: mechanism and role as an emergency signal for plant biodefence-a review. Gene 179, 45-51. doi: 10.1016/S0378-1119(96)00423-4

Dong, S., Yin, W., Kong, G., Yang, X., Qutob, D., Chen, Q., et al. (2011). Phytophthora sojae avirulence effector Avr3b is a secreted NADH and ADPribose pyrophosphorylase that modulates plant immunity. PLoS Pathog. 7:e1002353. doi: 10.1371/journal.ppat.1002353

Eloy, Y. R., Vasconcelos, I. M., Barreto, A. L., Freire-Filho, F. R., and Oliveira, J. T. (2015). $\mathrm{H}_{2} \mathrm{O}_{2}$ plays an important role in the lifestyle of Colletotrichum gloeosporioides during interaction with cowpea [Vigna unguiculata (L.) Walp.]. Fungal Biol. 119, 747-757. doi: 10.1016/j.funbio.2015.05.001

Fabritius, A. L., Cvitanich, C., and Judelson, H. S. (2002). Stage-specific gene expression during sexual development in Phytophthora infestans. Mol. Microbiol. 45, 1057-1066. doi: 10.1046/j.1365-2958.2002.03073.x

Gamboa-Meléndez, H., Huerta, A. I., and Judelson, H. S. (2013). bZIP transcription factors in the oomycete Phytophthora infestans with novel DNAbinding domains are involved in defense against oxidative stress. Eukaryotic Cell 12, 1403-1412. doi: 10.1128/EC.00141-13

Gao, J., Cao, M., Ye, W., Li, H., Kong, L., Zheng, X., et al. (2015). PsMPK7, a stressassociated mitogen-activated protein kinase (MAPK) in Phytophthora sojae, is required for stress tolerance, reactive oxygenated species detoxification, cyst germination, sexual reproduction and infection of soybean. Mol. Plant Pathol. 16, 61-70. doi: 10.1111/mpp.12163

Gavino, P. D., Smart, C. D., Sandrock, R. W., Miller, J. S., Hamm, P. B., Lee, T. Y., et al. (2000). Implications of sexual reproduction for Phytophthora infestans in the United States: generation of an aggressive lineage. Plant Dis. 84, 731-735. doi: 10.1094/PDIS.2000.84.7.731

Goddemeier, M. L., Wulff, D., and Feix, G. (1998). Root-specific expression of a Zea mays gene encoding a novel glycine-rich protein, zmGRP3. Plant Mol. Biol. 36, 799-802. doi: 10.1023/A:1005998804622

Grenville-Briggs, L. J., Horner, N. R., Phillips, A. J., Beakes, G. W., and West, P. V. (2013). A family of small tyrosine rich proteins is essential for oogonial and oospore wall development of the mycoparasitic oomycete Pythium Oligandrum. Fungal Biol. 117, 163-172. doi: 10.1016/j.funbio.2013.01.001

Guo, L. Y., Zhu, X. Q., Hu, C. H., and Ristaino, J. B. (2010). Genetic structure of Phytophthora infestans populations in China indicates multiple migration events. Phytopathology 100, 997-1006. doi: 10.1094/PHYTO-05-09-0126

Haas, B. J., Kamoun, S., Zody, M. C., Jiang, R. H., Handsaker, R. E., Cano, L. M., et al. (2009). Genome sequence and analysis of the Irish potato famine pathogen Phytophthora infestans. Nature 461, 393-398. doi: 10.1038/nature08358

Han, M., Liu, G., Li, J. P., Govers, F., Zhu, X. Q., Shen, C. Y., et al. (2012). Phytophthora infestans field isolates from Gansu Province, China are Genetically highly diverse and show a high frequency of self fertility. J. Eukaryot. Microbiol. 60, 79-88. doi: 10.1111/jeu.12010

Harris, H., and Hopkinson, D. A. (1987). Chapter 4 Handbook of Enzyme Electrophoresis in Human Genetics,. Amsterdam: North-Holland Publishing Co.

Hegnauer, H., and Hohl, H. R. (1978). Cell wall architecture of sporangia, chlamydospores, oogonia and oospores in Phytophthora. Exp. Mycol. 2, 216-233. doi: 10.1016/S0147-5975(78)80015-2

Hemmes, D. E. (1983). “Cytology of phytophthora," in Phytophthora: Its Biology, Taxonomy, Ecology, and Pathology, eds D. C. Erwin, S. Bartnicki-Garcia, and P. H. Tsao (St. Paul, MN: The American Phytopathological Society), 28-34.

Hemmes, D. E., and Bartnicki-Garcia, S. (1975). Electron microscopy of gametangial interaction and oospore development in Phytophthora capsici. Arch. Microbiol. 103, 91-112. doi: 10.1007/BF00436336

Hemmes, D. E., and Ribeiro, O. K. (1977). Electron microscopy of early gametangial interaction in Phytophthora megasperma var. sojae. Can. J. Bot. 55, 436-447. doi: 10.1094/PDIS.2000.84.11.1190

Ho, H. H. (1979). Electron microscope studies of oogonial wall and elemental composition of oogonia in phytophthora. Mycopathologia 68, 17-21. doi: 10.1007/BF00490386

Hohl, D., Olano, B. R., de Viragh, P. A., Huber, M., Detrisac, C. J., Schnyder, U. W., et al. (1993). Expression patterns of loricrin in various species and tissues. Differentiation 54, 25-34. doi: 10.1111/j.1432-0436.1993.tb00656.x

Kalinin, A., Marekov, L. N., and Steinert, P. M. (2001). Assembly of the epidermal cornified cell envelope. J. Cell. Sci. 114, 3069-3070.

Karling, J. S. (1981). Predominantly holocarpic and eucarpic simple biflagellate phycomycetes. J. Carmer. 252, 557-558.

Koch, E., and Slusarenko, A. (1990). Arabidopsis is susceptible to infection by a downy mildew fungus. Plant Cell 2, 437-445. doi: 10.1105/tpc.2.5.437

Küster, H., Schröder, G., Frühling, M., Pich, U., Rieping, M., Schubert, I., et al. (1995). The nodule- specific VfENOD-GRP3 gene encoding a glycine-rich early nodulin is located on chromosome I of Vicia faba L. and is predominantly expressed in the interzone II-III of root nodules. Plant Mol. Biol. 28, 405-421. doi: $10.1007 / \mathrm{BF} 00020390$ 
Larkin, M. A., Blackshields, G., Brown, N. P., Chenna, R., McGettigan, P. A., McWilliam, H., et al. (2007). Clustal W and Clustal X version 2.0. Bioinformatics 23, 2947-2948. doi: 10.1093/bioinformatics/btm404

Lippman, E., Erwin, D. C., and Bartnicki-Garcia, S. (1974). Isolation and chemical composition of oospore-oogonium walls of Phytophthora magasperma var. sojae. J. Gen. Microbiol. 80, 131-141. doi: 10.1099/0022128780-1-131

Liu, Z., and Friesen, T. (2012). DAB staining and visualization of hydrogen peroxide in wheat leaves. Bioprotocol 2:e309. doi: 10.21769/bioprotoc.309

Lledias, F., Rangel, P., and Hansberg, W. (1998). Oxidation of Catalase by Singlet Oxygen. J. Biol. Chem. 273, 10630-10637. doi: 10.1074/jbc.273.17.10630

Mangeon, A., Junqueira, R. M., and Sachetto-Martins, G. (2010). Functional diversity of the plant glycine-rich proteins superfamily. Plant Signal. Behav. 5, 99-104. doi: 10.4161/psb.5.2.10336

Mangeon, A., Pardal, R., Menezes-Salgueiro, A. D., Duarte, G. L., de Seixas, R., Cruz, F. P., et al. (2016). AtGRP3 Is implicated in root size and aluminum response pathways in Arabidopsis. PLoS ONE 11:e0150583. doi: 10.1371/journal.pone.0150583

Mayfield, J. A., and Preuss, D. (2000). Rapid initiation of Arabidopsis pollination requires the oleosin-domain protein GRP17. Nat. Cell. Biol. 2, 128-130. doi: $10.1038 / 35000084$

Mayton, H., Smart, C. D., Moravec, B. C., Mizubuti, E. S. G., Muldoon, A. E., and Fry, W. E. (2000). Oospore survival and pathogenicity of single oospore recombinant progeny from a cross involving the US-8 and US-17 lineages of Phytophthora infestans. Plant Dis. 84, 1190-1196. doi: 10.1094/PDIS.2000.84.11.1190

Mcleod, A., Fry, B. A., Zuluaga, A. P., Kevin, M., and Fry, W. E. (2008). Toward improvements of oomycete transformation protocols. J. Eukaryot. Microbiol. 55, 103-109. doi: 10.1111/j.1550-7408.2008.00304.x

Mellersh, D. G., Foulds, I. V., Higgins, V. J., and Heath, M. C. (2002). $\mathrm{H}_{2} \mathrm{O}_{2}$ plays different roles in determining penetration failure in three diverse plant-fungal interactions. Plant J. 29, 257-268. doi: 10.1046/j.0960-7412.2001.01215.x

Molina, L., and Kahmann, R. (2007). An Ustilago maydis gene involved in $\mathrm{H}_{2} \mathrm{O}_{2}$ detoxification is required for virulence. Plant Cell 19, 2293-2309. doi: $10.1105 /$ tpc.107.052332

Nithya, S., Radhika, T., and Jeddy, N. (2015). Loricrin - an overview. J. Oral. Maxillofac. Pathol. 19, 64-68. doi: 10.4103/0973-029X.157204

Park, S. J., Kwak, K. J., Oh, T. R., Kim, Y. O., and Kang, H. (2009). Cold shock domain proteins affect seed germination and growth of Arabidopsis thaliana under abiotic stress conditions. Plant Cell Physiol. 50, 869-878. doi: $10.1093 / \mathrm{pcp} / \mathrm{pcp} 037$

Prakob, W., and Judelson, H. S. (2007). Gene expression during oosporogenesis in heterothallic and homothallic Phytophthora. Fungal Genet. Biol. 44, 726-739. doi: 10.1016/j.fgb.2006.11.011

Ribeiro, O. K. (1978). A Source Book of the Genus Phytophthora. Vaduz: Cramer.

Ribeiro, O. K. (1983). "Physiology of asexual sporulation and spore germination in Phytophthora," in Phytophthora: Its Biology, Taxonomy, Ecology, and Pathology, eds D. C. Erwin, S. Bartnicki-Garcia, and P. H. Tsao, (St. Paul, MN: The American Phytopathological Society), 58-60.

Ringli, C., Hauf, G., and Keller, B. (2001). Hydrophobic interactions of the structural protein GRP1.8 in the cell wall of protoxylem elements. Plant Physiol. 125, 673-682. doi: 10.1104/pp.125.2.673

Ryser, U., and Keller, B. (1992). Ultrastructural localization of a bean glycine-rich protein in unlignified primary walls of protoxylem cells. Plant Cell. 4, 773-783. doi: $10.1105 /$ tpc.4.7.773

Ryser, U., Schorderet, M., Zhao, G. F., Studer, D., Ruel, K., Hauf, G., et al. (1997). Structural cell-wall proteins in protoxylem development: evidence for a repair process mediated by a glycine-rich protein. Plant J. 12, 97-111. doi: 10.1046/j.1365-313X.1997.12010097.x

Sanju, S., Siddappa, S., Thakur, A., Shukla, P. K., Srivastava, N., Pattanayak, D., et al. (2015). Host-mediated gene silencing of a single effector gene from the potato pathogen Phytophthora infestans imparts partial resistance to late blight disease. Funct. Integr. Genomics. 15, 697-706. doi: 10.1007/s10142-015-0446-Z

Sheng, Y., Wang,. Y., Meijer, H. J., Yang, X., Hua, C., Ye, W., et al. (2015). The heat shock transcription factor PsHSF1 of Phytophthora sojae is required for oxidative stress tolerance and detoxifying the plant oxidative burst. Environ. Microbiol. 17, 1351-1364. doi: 10.1111/1462-2920.12609

Sogin, M. L., and Silberman, J. D. (1998). Evolution of the protists and protistan parasites from the perspective of molecular systematics. Int. J. Parasitol. 28, 11-20. doi: 10.1016/S0020-7519(97)00181-1

Sparrow, F. K. (1960). Aquatic Phycomycetes 2nd Revised Edition. Ann Arbor, MI: University of Michigan Press, 1187.

Tamura, K., Peterson, D., Peterson, N., Stecher, G., Nei, M., and Kumar, S. (2011) MEGA5: molecular evolutionary genetics analysis using maximum likelihood, evolutionary distance, and maximum parsimony methods. Mol. Biol. Evol. 28, 2731-2739. doi: 10.1093/molbev/msr121

Torres, M. A., and Dangl, J. L. (2005). Functions of the respiratory burst oxidase in biotic interactions, abiotic stress and development. Curr. Opin. Plant Biol. 8, 397-403. doi: 10.1016/j.pbi.2005.05.014

Torto, T. A., Rauser, L., and Kamoun, S. (2002). The pipg1 gene of the oomycete Phytophthora infestans encodes a fungal-like endopolygalacturonase. Curr. Genet. 40, 385-390. doi: 10.1007/s00294-002-0272-4

Turkensteen, L. J., Flier, W. G., Wanningen, R., and Mulder, A. (2000). Production, survival and infectivity of oospores of Phytophthora infestans. Plant Pathol. 49, 688-696. doi: 10.1046/j.1365-3059.2000.00515.x

Ueki, S., and Citovsky, V. (2002). The systemic movement of a tobamovirus is inhibited by a cadmium-ion-induced glycine-rich protein. Nat. Cell Biol. 4, 478-486. doi: 10.1038/ncb806

Wang, Y., Dong, Q., Ding, Z., Gai, K., Han, X., Kaleri, F. N., et al. (2016). Regulation of Neurospora Catalase-3 by global heterochromatin formation and its proximal heterochromatin region. Free Radic Biol. Med. 99, 139-152. doi: 10.1016/j.freeradbiomed.2016.07.019

Yoon, H. S., Hackett, J. D., Pinto, G., and Bhattacharya, D. (2002). The single, ancient origin of chromist plastids. Proc. Natl. Acad. Sci. U.S.A. 99, 15507-15512. doi: 10.1073/pnas.242379899

Zhao, W., Dong, S., Ye, W., Hua, C., Meijer, H. J., Dou, X., et al. (2011). Genomewide identification of Phytophthora sojae SNARE genes and functional characterization of the conserved SNARE PsYKT6. Fungal Genet. Biol. 48, 241-251. doi: 10.1016/j.fgb.2010.11.006

Zhao, W., Wang, T., Liu, S. S., Chen, Q. Q., and Qi, R. D. (2015). The histone acetyltransferase PsGcn5 mediates oxidative stress response and is required for full virulence of Phytophthora sojae. Microb. Pathog. 87, 51-58. doi: 10.1016/j.micpath.2015.07.015

Conflict of Interest Statement: The authors declare that the research was conducted in the absence of any commercial or financial relationships that could be construed as a potential conflict of interest.

Copyright (c) 2017 Guo, Wang, Shan, Sun and Guo. This is an open-access article distributed under the terms of the Creative Commons Attribution License (CC BY). The use, distribution or reproduction in other forums is permitted, provided the original author(s) or licensor are credited and that the original publication in this journal is cited, in accordance with accepted academic practice. No use, distribution or reproduction is permitted which does not comply with these terms. 